\title{
REVIEW
}

Open Access

\section{Perinatal mortality and its determinants in Sub Saharan African countries: systematic review and meta-analysis}

\author{
Dawit Tiruneh $^{1 *} \mathbb{D}$, Nega Assefa ${ }^{2}$ and Bezatu Mengiste ${ }^{3}$
}

\begin{abstract}
Background: Despite decreasing overall perinatal and maternal mortality in high-income countries, perinatal and maternal health inequalities are persisting in Sub Saharan African countries. Therefore, this study aimed to determine the effects size of rates and determinants for perinatal mortality in Sub-Saharan countries.

Method: The sources for electronic datasets were PubMed, Medline, EMBASE, SCOPUS, Google, Google Scholar, and WHO data Library. Observational studies published in the English language from January 01, 2000, to May 30, 2019 were included. STROBE and JBI tools were used to include relevant articles for this review. We used a Comberehensive Meta-Analysis version 2 software for this analysis. The $\mathrm{I}^{2}$ and Q- statistic values were used to detect the level of heterogeneity. The Kendall's without continuity correction, Begg and Mazumdar rank correlation and Egger's linear regression tests were used to detect the existence of significant publication bias $(P<0.10)$. The effects size were expressed in the form of point estimate and odds ratio with $95 \% \mathrm{Cl}(P<0.05)$ in the random effect analysis using the trim and fill method.
\end{abstract}

Result: Twenty-one articles were included in this review. However, only fourteen studies reported the perinatal mortality rate. Among 14 studies, the observed and adjusted PMR was found to be 58.35 and 42.95 respectively. The odds of perinatal mortality among mothers who had no ANC visits was $2.04(\mathrm{Cl}: 1.67,2.49, P<0.0001)$ as compared to those who had at least one ANC visit. The odds of perinatal mortality among preterm babies was 4.42 (Cl: 2.83, 6.88, $P<0.0001)$. In most cases, heterogeneity was not evident when subgroup analyses were assessed by region, study design, and setting. Only perinatal mortality $(P<0.0001)$, antenatal care $(P<0.046)$ and preterm births $(P<0.034)$ showed a relationship between the standardized effect sizes and standard errors of these effects.

Conclusion: In general, engaging in systematic review and meta-analysis would potentially improve under-represented strategies and actions by informing policy makers and program implementers for minimizing the existing socioeconomic inequalities between regions and nations.

Keywords: Perinatal mortality, Determinants, Random effect, Effect size, Heterogeneity, Publication Bias, Sensitivity, SubSaharan

\footnotetext{
* Correspondence: dawit2h2005@gmail.com

'Department of Midwifery, College of Health Sciences, Debre Tabor

University, National State of Amhara, Debre Tabor Town, South Gondar Province, Ethiopia

Full list of author information is available at the end of the article
}

(c) The Author(s). 2021 Open Access This article is licensed under a Creative Commons Attribution 4.0 International License, which permits use, sharing, adaptation, distribution and reproduction in any medium or format, as long as you give appropriate credit to the original author(s) and the source, provide a link to the Creative Commons licence, and indicate if changes were made. The images or other third party material in this article are included in the article's Creative Commons licence, unless indicated otherwise in a credit line to the material. If material is not included in the article's Creative Commons licence and your intended use is not permitted by statutory regulation or exceeds the permitted use, you will need to obtain permission directly from the copyright holder. To view a copy of this licence, visit http://creativecommons.org/licenses/by/4.0/ The Creative Commons Public Domain Dedication waiver (http://creativecommons.org/publicdomain/zero/1.0/) applies to the data made available in this article, unless otherwise stated in a credit line to the data. 


\section{Background}

Perinatal mortality is the best indicator of the quality of prenatal, delivery, and early infant care practices available in any circumstances. It contributed to $40 \%$ of deaths to overall under-five mortality $[1,2]$. Reducing inequities and reaching the most vulnerable children are the emphases of all concerned bodies for ending preventable deaths of newborns and children under five years of age by 2030. According to the United Nations (UNs) reports in 2017, 1 in 36 infants die in the first month of life in sub-Saharan Africa as compared with 1 in 333 in high-income countries [2].

Maintaining an effective balance between preserving normality and ensuring a state of readiness in an attempt to reduce this gap represents a fundamental challenge to health systems and a tension in safe motherhood programming in Sub-Saharan countries [3-6]. Perinatal and maternal health inequalities are persistently high and remain beyond the acceptable level in low-income countries of Africa. In addition, perinatal mortality indicates the extent of pregnancy wastage and the quality and quantity of health care services available to the mother and the newborn [5]. Globally, an estimated 2.6 million stillbirths occur each year. Of these, half of them occur during labor and birth. Most stillbirths result from preventable conditions such as maternal infections, noncommunicable diseases, and obstetric complications [6].

Ending preventable perinatal death is high on the international public health concern even though there is slow progress in preventing perinatal deaths [7]. However, improving people's health and quality of life requires collective actions for equity of fair distribution of resources and addressing disparities of health inequities between regions, especially in rural and urban areas [8]. As part of the Early Neonatal Action Plan (ENAP), the World Health Organization (WHO) is developing a perinatal audit as a means to assist in addressing modifiable factors. Its focus is creating a link to a minimum perinatal dataset [9] after the UN 2030 agenda embraces good health is a precondition for outcome and measure of sustainable development program. The UN 2030 agenda is targeting to reduce MMR to less than 70 per 100,000 live births, NMR to less than 12/1000 live births, and under-five mortality rate to less than 25 per 1000 live birth [10]. In general, collective efforts and actions taken into account in the era of sustainable development programs should be implemented based on the nation's cultural, economic, and societal contexts.

Although there are discrepancies between studies in Sub-Saharan regions, no systematic review or metaanalysis studies exist in the study area. This review allows health care providers, researchers, and policymakers to efficiently integrate existing information and provide data for decision-making in the most relevant context of perinatal health. Therefore, the current systematic review and meta-analysis aimed to determine the pooled estimate of the perinatal mortality rate and the effects sizes of determinants for perinatal mortality. It aims to help identify the root causes of discrepancies between studies in Sub Saharan African countries.

\section{Method}

\section{Search strategy}

Studies for this review and meta-analysis were accessed in electronic web-based searches using different search engines. Published articles in the English language were intensively accessed and examined to minimize the level of publication and selection bias. The sources for electronic datasets were PubMed, Medline, EMBASE, SCOPUS, Google, Google Scholar, and WHO data Library. The ancestor search strategy was accessed, aiming to arrive at the final number of studies. Studies that were cited by others were also looked online (descendent search strategy). In combination with $\mathrm{MeSH}$ terms, we used the Boolean operator 'AND' and 'OR' to connect and focus a search from Pubmed. The search terms we used include incidence, prevalence, rate, ratio, risk factors, determinant, perinatal mortality, perinatal death, stillbirth, early neonatal death and sub-Saharan' (Table 1).

\section{Eligibility criteria}

The methodological qualities and the outcome of each study was critically examined in the review process. Studies were included in the review if the study:

- was conducted on perinatal mortality in non-Arab state members of the Sub-Saharan countries in Africa

- was published in the English language from January 01, 2000, to May 30, 2019 Gregorian calendar (GC)

- was observational study design

- design was cross-sectional, case-control or cohort

- was conducted based on the definition of classification for perinatal mortality and its determinants

\section{Definition of the outcome of interest}

The outcomes of interest in this review were perinatal mortality and eight selected determinants of perinatal mortality in Sub-Saharan African countries.

- The perinatal period: It commences at 28 completed weeks (154 days) of gestation and ends seven completed days after birth.

- The perinatal mortality rate: The sum of stillbirth rate and early neonatal mortality rate within the first week of life 
Table 1 Pubmed search strategies and search details for perinatal mortality and its determinants

\begin{tabular}{lll}
\hline $\begin{array}{l}\text { S. } \\
\text { No. }\end{array}$ & Search terms and strategies & Examples of search details \\
\hline $\mathbf{1}$ & $\begin{array}{l}\text { Incidence/prevalence AND rate/ } \\
\text { ratio }\end{array}$ & $\begin{array}{l}\text { "((Incidence/prevalence[All Fields]AND("risk factors "[MeSH Terms] OR ("risk"[All Fields] AND "factors"[All Fields]) } \\
\text { OR "risk factors"[All Fields] AND determinant[All Fields] AND ("perinatal mortality"[MeSH Terms] OR } \\
(" \text { perinatal"[All Fields])))" }\end{array}$ \\
$\mathbf{2}$ & $\begin{array}{l}\text { Risk factors AND/OR determinant } \\
\mathbf{3}\end{array}$ & $\begin{array}{l}\text { Perinatal mortality AND/OR } \\
\text { perinatal death }\end{array}$ \\
$\mathbf{4}$ & $\begin{array}{l}\text { Outcome/death AND/OR still birth } \\
\mathbf{5}\end{array}$ & $\begin{array}{l}\text { Early neonatal death AND/OR } \\
\text { neonatal death }\end{array}$ \\
$\mathbf{6}$ & Sub AND Saharan \\
\hline
\end{tabular}

- Stillbirth: A baby born with no signs of life at or after 28 weeks' gestation or birth weight of $1000 \mathrm{~g}$ or more or body length of $35 \mathrm{~cm}$ or more [1]

\section{Study identification and selection}

During the data extraction process, we used the reviewers' manual data extraction form that has been developed by the 2014 JBI institute. The information on the title, author, publication year, study design, sample size, study participants, sampling methods, and outcome of interest were considered in the selection process. The first author conducted the primary searching of studies from different sources. Initially, our colleagues (AA and SB) searched and identified potential articles using predetermined selection criteria. Following the identification, DT made the final selection through a critical review of full-text articles. Co-authors (NA and BM) closely supervised the selection process. In this review, we excluded full-text articles that failed to report sufficient sample statistics or raw data. In general, no study was excluded without a thorough evaluation using STROBE critical appraisal [11] and JBI quality assessment tools [12]. The final quality score was set for each study design by discussion.

\section{Data abstraction}

This review was conducted from June 01, 2019, to July 24, 2019, using the STROBE critical appraisal tools. We further assessed studies using the checking points in the JBI quality assessment tool. For each study design, we included a study that scored above the mean value of the checking points. We used the preferred reporting Item for Systematic Review and Meta-Analyses (PRIS MA 2009) to arrive at the final 21 included articles [13].

We assessed the study objectives, designs, period, location, settings, generalizability, and relevance to the study population of the primary articles. Statistically significant variables and statistical analysis models on topics related to the current research were extracted, retrieved, and included. After removing duplicated studies, we excluded irrelevant articles' titles and abstracts. Then, we excluded abstracts that failed to show relationships of associated variables with perinatal mortality. Finally, we excluded full-text studies which did not fulfill the predetermined criteria of the review.

\section{Heterogeneity}

We assessed the presence of heterogeneity using the Chi-square statistic (Cochran's-Q), Tau $\left(\tau^{2}\right)$ and Isquared $\left(\mathrm{I}^{2}\right)$ with their corresponding $P$-value. We used the Chi-square statistic $(\mathrm{Q})$ to determine the extent of heterogeneity across studies. A Q - statistic more than the chi-square value corresponding to the degree of freedom, and $P<0.05$ indicates the presence of heterogeneity $[14,15]$. The $\tau^{2}$ and $\mathrm{I}^{2}$ statistics were used to assess the heterogeneity of studies within and between studies, respectively [16]. We determined the extent of heterogeneity as mild (25\%), moderate (50\%), and high (75\%) heterogeneity. An $\mathrm{I}^{2}$ of zero means that all variability in effects size estimates is due to sampling error within studies $[17,18]$.

\section{Publication bias}

We assessed the presence of publication bias using the funnel plot asymmetry, the Begg and Mazumdar rank correlation and Egger's linear regression. Using the visual presentation of the funnel plot for detecting asymmetry and the Kendall's $S$ statistics score (P-Q) for showing the direction of the correlation were subjective to detect the presence of publication bias. Therefore, the $\tau^{2}$ statistical significance $(P<0.10)$, Kendall's without continuity correction and Egger's linear regression tests were used to detect the possible existence of significant publication bias $(p<0.10)$ at a $95 \%$ confidence interval for statistical analysis $[16,19-21]$.

\section{Sensitivity analysis}

In this study, the robustness of the findings were examined through sensitivity analysis. It was used to assess the presence of publication bias, the effect of study quality, and the results of the effect size. We conducted a sensitivity analysis with large and small effect size 
outliers using inferential statistics of this meta-analysis [22, 23]. Regarding removing one sample, we repeated the meta-analysis multiple times, each time leaving out one sample to analyze the distribution mean change when a given sample is excluded from the analysis considering the results of influential samples [24].

\section{Statistical analysis}

We used an excel sheet to extract and organize the necessary information from each original study. Both the observed and adjusted point estimates were expressed in the form of event rate per 1000 total births for perinatal mortality and odds raios with the associated 95\% CI in the random-effects model. The random-effects model was selected to estimate the pooled effect size of the perinatal mortality rate and its purposely selected determinants using a Comprehensive Meta-Analysis (CMA) version 2 software [25]. The model assumes that primary studies might differ in the implementations of interventions and selection of participants. Also, the effect sizes in the original studies might represent a random sample from a particular distribution of these effects size [16].

Also, to test the statistical significance of differences between groups and compare the mean effects of two or more groups, subgroup analyses were conducted using regions, study settings, and designs [26]. The adjusted effect size was determined by applying Duval and Tweedie's trim and fill method in the random-effects analysis
[27]. Duval and Tweedie's procedure stated that if the point estimate was to be adjusted for bias left or right of the mean, it would remain unchanged for the randomeffects model [16]. Forest plot, high resolution, and funnel plot tests displayed the results of the mean effect sizes in the form of event rate and odds ratio.

\section{Result}

\section{Systematic review results}

A total of 351 articles were retrieved through electronic searching by titles and abstracts. Of these records, we arrived at 21 eligible studies to estimate the observed and adjusted effect sizes, the extent of heterogeneity, and the existence of publication bias for perinatal mortality rate and its selected determinants (Fig. 1).

\section{Description of studies}

Of the 21 included studies, eight were cross-sectional, six were case-control, and seven were cohort studies. Regarding the study setting, eleven were in the facility, eight were in the community, and only two were population-based studies. These review included studies from Ethiopia [28-32], Nigeria [33-36], Tanzania [37, 38], Zimbabwe [5, 39], Uganda, Ghana [40], Côte d'Ivoire [41], Burkina Faso [42], Kenya [43], Rwanda [44], Malawi [45], and Mozambique [46]. Most studies in Ethiopia and Nigeria were eligible and presented in this review. We included studies published from 2000 to

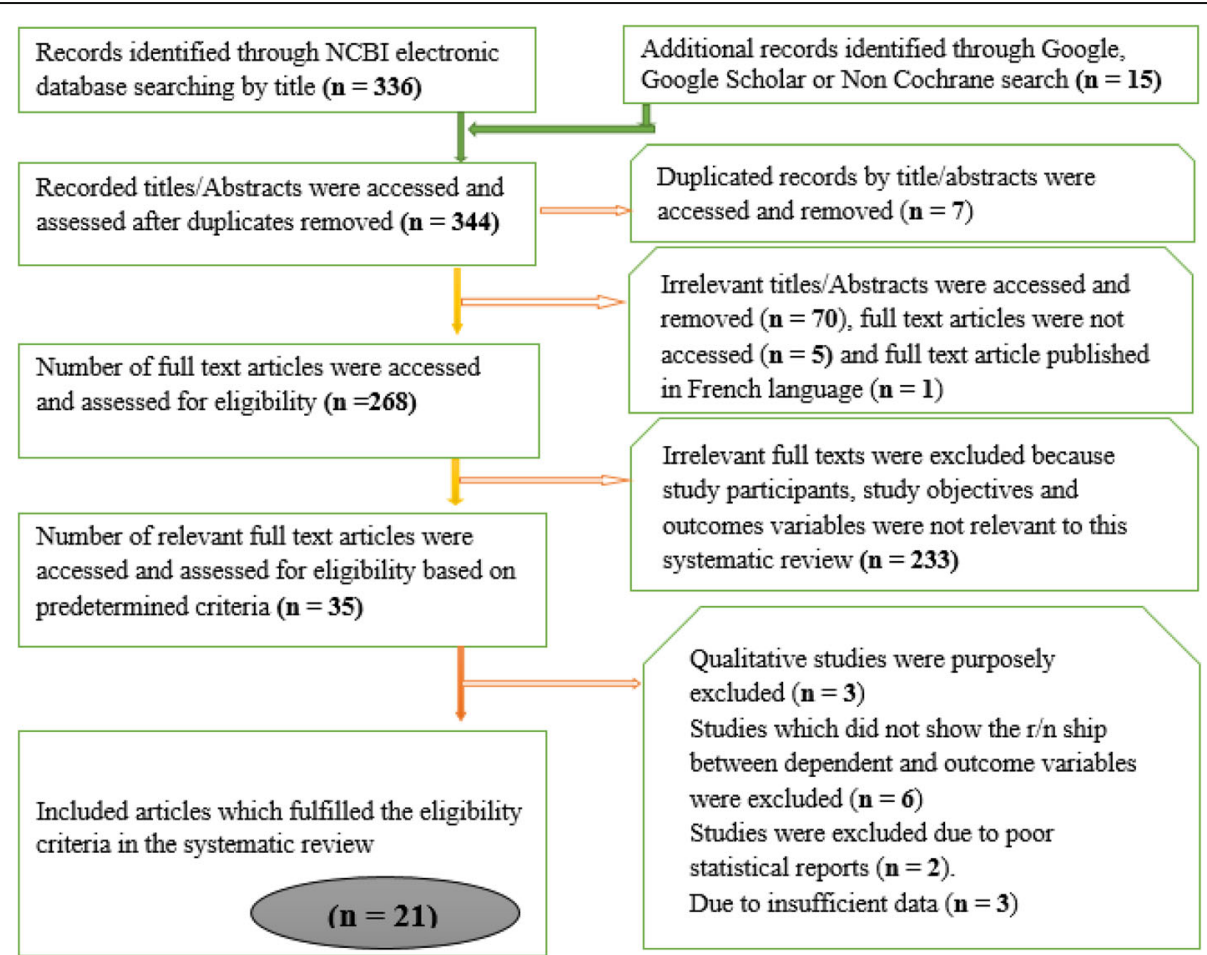

Fig. 1 Steps of selecting relevant articles using the PRISMA Group (Moher et al., 2009). Preferred Reporting Items for Systematic Reviews and Meta-Analyses 
2019 Gregorian Calendar (GC), and the sample size ranges from 378 in Ethiopia [31] to a maximum of 25, 817 in Nigeria [33]. Ethiopia [30] and Uganda reported the lowest and the highest perinatal mortality rate, respectively. Overall, studies included in this review have a total sample size of 118,372 pregnant mothers in the Sub-Saharan region (Table 2).

\section{Perinatal mortality}

Of the 21 eligible studies, only fourteen studies reported perinatal mortality rates in the Sub-Saharan region and the reports showed us discrepancies of perinatal mortality rate in Sub-Saharan countries. All fourteen studies reporting perinatal mortality rate were eligible and included in the meta-analysis to assess the pooled effects size of the perinatal mortality rates. The overall observed perinatal mortality rate was 58.35 (95\% CI: 46.19, 70.51, $P<0.0001$ ) per 1000 total births (stillbirth and live births) in the random-effect analysis (Fig. 2). Four studies were slimmed to estimate the adjusted effect sizes of perinatal mortality rates in Sub-Saharan countries (Pooled PMR: 42.95, 95\% CI: 29.21, 56.70).

\section{Subgroup analysis and perinatal mortality}

We conducted subgroup analyses to estimate the mean effect sizes of perinatal mortality in three regions of Africa (West Africa, East Africa, and South Africa). Studies in West Africa showed the highest perinatal mortality rate, 65.07 (95\% CI: 47.07, 83.07) as compared to studies in East Africa, 49.88 (95\% CI: 28.59, 71.18), and South Africa, 56 (95\% CI: 22.33, 89.67). The rates were high in a facility-based study setting, 64.09 (95\% CI: 46.00, 82.2), and cross-sectional study design, 68.82 (95\% CI: 53.83, 83.81). The $\mathrm{I}^{2}$ test showed high levels of heterogeneity by region, study setting, and study design with a strong statistical significance $(P<0.001)$ (Table 3$)$.

\section{Sensitivity analysis and perinatal mortality}

We conducted a sensitivity analysis to reduce the level of heterogeneity between studies. We removed some outlier studies having small and high relative weight. Because they might potentially affect the estimation of the true effect size. Two studies in Ethiopia [30] and Uganda [39] showed the highest (13.69\%) and the smallest relative weight $(3.24 \%)$ respectively. When these studies were excluded and running the analysis, the cumulative perinatal mortality rate was slightly lowered to 57.16 (45.67, 68.65, $P<0.0001)$. Similarly, when we performed removing one study in the meta-analysis using the CMA software, the $\mathrm{CI}$ of each became narrower. However, we did not see a change in the overall rate of perinatal mortality (Fig. 3).

\section{Determinants and perinatal mortality rate}

In the random-effects analysis, we purposely selected only eight determinants from 21 eligible studies of perinatal mortality in Sub-Saharan countries. These were low birth weight less than $2500 \mathrm{~g}$, primiparity, presence of ANC visits, history of abortion or perinatal loss, multiple gestation (two or more), preterm birth less than 37 completed weeks, birth interval less than two years, and mode (non-spontaneous) of delivery. There was a statistically significant association between these determinants and perinatal mortality in the study region.

\section{Low birth weight and perinatal mortality}

In this meta-analysis, seven studies [5, 28-30, 36, 43, 46] were included. The observed odds ratio of low birth weight for the risk of perinatal mortality was 8.69 (CI: $6.04,12.51, P<0.001)$ as compared to babies born with an adequate birth weight (2500-3999 g) (Table 4). In this analysis, observed and adjusted effect sizes of low birth weight were equal, revealed no studies were slimmed to adjust publication bias. However, there was a moderate level of heterogeneity in the study region $\left(\mathrm{I}^{2}: 35.19, \mathrm{Q}\right.$ : $9.26, P>0.16)$. In the subgroup analysis by region, there was a moderate level of heterogeneity in East African studies $\left(\mathrm{I}^{2}: 56.72\right.$, Q: 6.93, $\left.P>0.74\right)$. However, it was not evident in total studies by region (Q: 0.44 , df: $2, P>$ $0.802)$, study setting (Q: 0.032 , df: $2, P>0.859)$ and study design (Q: 2.166, df: $2, P>0.339$ ).

\section{Primiparity and perinatal mortality}

In this category of meta-analysis, five studies [35, 36, 39, $40,42]$ were included. The observed odds ratio of primiparity for the risk of perinatal mortality was 1.56 (CI: $1.18,2.05, P<0.002$ ) (Table 5). As for birth weight, observed and adjusted values were equal revealing that no studies were slimmed to estimate the final effect sizes of primiparity for perinatal mortality. A moderate level of heterogeneity was observed $\left(\mathrm{I}^{2}: 32.06, \mathrm{Q}: 5.89\right.$, df: $4, P>$ $0.208)$. In subgroup analysis, a moderate level of heterogeneity was observed in West African studies $\left(\mathrm{I}^{2}: 45.15\right.$, Q: 5.47 df: $3, P>0.14)$, facility-based studies $\left(\mathrm{I}^{2}: 56.66\right.$, $\mathrm{Q}:$ 4.62, df: $2, \mathrm{P}>0.1)$ and cohort study designs $\left(\mathrm{I}^{2}\right.$ : 71.43, Q: 3.50, df: $1, P>0.061)$. But, it was not evident in total studies by region (Q: 0.395 , df: $1, P>0.53$ ), study setting (Q: 0.95, df: 2, $P>0.623$ ) and study design (Q: 0.19 , df: $1, P>0.664)$.

\section{ANC visits and perinatal mortality}

Five studies [29, 31, 34, 39, 43] were included in this meta-analysis. The observed odds ratio of no ANC visit was 2.04 (CI: $1.67,2.49, P<0.001$ ) for the risk of perinatal mortality as compared to those who had at least one ANC visit (Table 6). Two studies were filled to estimate the adjusted effect sizes of ANC visits (POR: 1.99, 
Table 2 Characteristics of included articles for systematic review for perinatal mortality rate in Sub-Saharan countries, 2000-2019 Gregorian Calendar (GC)

\begin{tabular}{|c|c|c|c|c|c|c|c|}
\hline Author, Year & $\mathbf{R}$ & $\mathrm{S}$ & D & SS & Determinants & $\begin{array}{l}\text { Association with } \\
\text { PMR AOR(95\% CI) }\end{array}$ & PMR \\
\hline \multirow[t]{4}{*}{ Getiye et al., 2017, [28] Ethiopia } & EA & $\mathrm{FB}$ & $\mathrm{CC}$ & 1113 & Short birth interval & $4.55(1.79-11.54)$ & NR \\
\hline & & & & & Preterm Delivery & $2.02(1.08-3.77)$ & \\
\hline & & & & & Hx of perinatal loss & $6.36(1.51-26.76)$ & \\
\hline & & & & & Low Birth weight & $16.45(9.57-28.26)$ & \\
\hline \multirow[t]{4}{*}{ Aragaw YA, 2016, [29] Ethiopia } & EA & $\mathrm{FB}$ & CS & 3786 & No ANC visit & $2.05(1.48-2.87)$ & 98.2 \\
\hline & & & & & Shoulder delivery & $5.95(2.11-16.86)$ & \\
\hline & & & & & Breech delivery & $4.06(1.856-8.912)$ & \\
\hline & & & & & Low birth weight & $5.03(1.63-15.00)$ & \\
\hline \multirow[t]{4}{*}{ Yirgu R et al., 2016, [30] Ethiopia } & EA & $\mathrm{CB}$ & $\mathrm{CC}$ & 4097 & Primipara & $3.15(1.03-9.60)$ & 25.1 \\
\hline & & & & & Hx of perinatal loss & $2.46(1.03,5.86)$ & \\
\hline & & & & & Hx of perinatal loss & $9.55(4.67-19.54)$ & \\
\hline & & & & & Preterm birth & $9.44(1.81-49.22)$ & \\
\hline \multirow[t]{4}{*}{ Goba et al. 2018, [31] Ethiopia } & EA & $\mathrm{FB}$ & $\mathrm{CC}$ & 378 & Preterm birth & $12.2(3.46,43.17)$ & NR \\
\hline & Z & & & & Low birth weight & $11.5(3.16-42.36)$ & \\
\hline & & & & & No ANC visit & $5.4(0.80-36.63)$ & \\
\hline & & & & & Short birth interval & $2.2(1.03-5.09)$ & \\
\hline \multirow[t]{3}{*}{ Andargie et al. 2013, [32] Ethiopia } & EA & $\mathrm{CB}$ & Co & 1752 & Hx of perinatal loss & $8.38(3.94,17.83)$ & 50.22 \\
\hline & & & & & Multiple gestation & $7.09(3.22,15.61)$ & \\
\hline & & & & & Short birth interval & $2.58(1.61,4.13)$ & \\
\hline \multirow[t]{4}{*}{ Nkwo et al., 2014, [33] Nigeria } & WA & PB & CS & 25,817 & Hx of perinatal loss & $3.31(2.73,4.02$ & 36 \\
\hline & & & & & Multiple gestation & $3.12(2.11,4.59)$ & \\
\hline & & & & & Short birth interval & $1.65(1.26,2.17)$ & \\
\hline & & & & & Low birth weight & $2.57(1.79,3.69)$ & \\
\hline \multirow[t]{4}{*}{ Fawole et al., 2011, [34] Nigeria } & WA & $\mathrm{FB}$ & CS & 9177 & No ANC visit & $1.74(1.27,2.39)$ & 78 \\
\hline & & & & & Preterm birth & $1.89(1.12,3.19)$ & \\
\hline & & & & & Elective CS & $0.12(0.05,0.36)$ & \\
\hline & & & & & Emergency CS & $0.73(0.55,0.96)$ & \\
\hline Owolabi et al. 2008, & WA & $\mathrm{FB}$ & $\mathrm{Co}$ & 894 & Primipara & $0.67(0.26,1.73)$ & NR \\
\hline \multicolumn{8}{|l|}{ [35] Nigeria } \\
\hline \multirow[t]{2}{*}{ Ekure et al. 2011, [36] Nigeria } & WA & $\mathrm{FB}$ & CS & 560 & Primipara & ${ }^{c} 0.07 \mathrm{~B}(0.02,0.06)$ & 84.6 \\
\hline & & & & & Low birth weight & ${ }^{c}-0.09 B(-0.05,0.02)$ & \\
\hline Schmiegelow et al. 2012, [37] Tanzania & EA & CB & $\mathrm{Co}$ & 872 & Preterm birth & $14.47(3.23,64.86)$ & NR \\
\hline Habib et al. 2008, [38] Tanzania & EA & $\mathrm{FB}$ & CS & 15,255 & Preterm birth & a $2.2(1.7,2.8)$ & 43.9 \\
\hline \multirow[t]{4}{*}{ Feresu et al. 2005, [39] Zimbabwe } & SA & $\mathrm{FB}$ & CS & 15,117 & No ANC visit & ${ }^{\mathrm{b}} 2.52(1.63,3.91)$ & 65 \\
\hline & & & & & Primipara & b $1.52(0.97,2.38)$ & \\
\hline & & & & & Breech Delivery & b $10.53(6.78,6.34)$ & \\
\hline & & & & & Instrument delivery & b $3.38(1.64,6.96)$ & \\
\hline Tachiweyika et al. 2011, [5] Zimbabwe & SA & $\mathrm{CB}$ & $\mathrm{CC}$ & 10,540 & Low birth weight & $9.46(3.91,27.65)$ & NR \\
\hline Moyer et al. 2016, [40] Uganda & WA & $\mathrm{CB}$ & CS & 4883 & - & - & 105.88 \\
\hline \multirow[t]{3}{*}{ Engmann et al. 2012, [41] Ghana } & WA & $\mathrm{PB}$ & CS & 17,300 & Primipara & $1.75(1.28,2.40)$ & 39 \\
\hline & & & & & Preterm birth & $2.84(2.11,3.81)$ & \\
\hline & & & & & Multiple gestation & $5.22(3.61,7.54)$ & \\
\hline Kone et al., 2018, [42] Côte d'Ivoire & WA & $C B$ & Co & 2976 & $\mathrm{Hx}$ of perinatal loss & $23.2(14.71,36.55)$ & 33 \\
\hline
\end{tabular}


Table 2 Characteristics of included articles for systematic review for perinatal mortality rate in Sub-Saharan countries, 2000-2019 Gregorian Calendar (GC) (Continued)

\begin{tabular}{|c|c|c|c|c|c|c|c|}
\hline Author, Year & $\mathbf{R}$ & $\mathrm{S}$ & D & SS & Determinants & $\begin{array}{l}\text { Association with } \\
\text { PMR AOR(95\% CI) }\end{array}$ & PMR \\
\hline & & & & & Preterm birth & $4.45(2.82,7.01)$ & \\
\hline & & & & & Caesarean section & $13.03(4.24,40.08)$ & \\
\hline & & & & & Instrument delivery & $5.05(1.50,16.96)$ & \\
\hline \multirow[t]{2}{*}{ Diallo et al. 2010, [43] Burkina Faso } & WA & $C B$ & $\mathrm{Co}$ & 895 & Primipara & $2.20(1.2,3.9)$ & 79 \\
\hline & & & & & Multiple gestation & b $4.0(2.3,6.9)$ & \\
\hline \multirow[t]{3}{*}{ Yego et al. 2014, [44] Kenya } & EA & $F B$ & $\mathrm{CC}$ & 600 & No ANC visit & $4.5(1.2,16.7)$ & NR \\
\hline & & & & & Preterm birth & $7.0(2.4,20.4)$ & \\
\hline & & & & & Low birth weight & $6.6(3.8,10.2)$ & \\
\hline Musafili et al. 2015, [45] Rwanda & EA & FB & $\mathrm{CC}$ & 672 & - & - & 32 \\
\hline \multirow[t]{2}{*}{ kulmala et al. 2000, [46] Malawi } & EA & $C B$ & Co & 780 & Cesarean section & b $4.4(1.4,13.9)$ & NR \\
\hline & & & & & Hx of perinatal loss & b $2.7(1.3,5.7)$ & \\
\hline N.B Osman et al. 2001, [47] & SA & $F B$ & Co & 908 & Preterm birth & $8.48(3.44,20.90)$ & 47 \\
\hline Mozambique & & & & & Low Birth weight & AOR $4.20(1.49-11.86)$ & \\
\hline
\end{tabular}

Association with PMR reported as adjusted odds ratio (95\% confidence interval) except as noted ${ }^{a}$ relative risk, ${ }^{\mathrm{b}}$ Adjusted Relative risk, and ${ }^{\mathrm{C}}$ Standard coeffiecent, Region (R) is coded: EA East Africa, SA South Africa, WA West Africa., Study type is coded, CB Community Based, FB Facility Based, PB Population Based, Study design is coded, CC Case control, Co Cohort, CS Cross Sectional, Sample size (SS) is coded, Perinatl mortality rate (PMR) is coded, NR Not Reported

CI: $1.60,2.46)$. In this category of meta-analysis, we only detected a mild level of heterogeneity in East Africa studies ( $\mathrm{I}^{2}: 7.27, \mathrm{Q}: 2.16$, df: $\left.2, P>0.34\right)$.

\section{History of perinatal loss and perinatal mortality}

Five studies $[28,30,32,33,41]$ were included. The observed odds ratio of history of perinatal loss for the risk of perinatal mortality was 8.34 (CI: $3.15,22.1, P<0.001)$ as compared to those mothers who had no history of perinatal loss (Table 7). Three studies were trimmed to estimate the adjusted effect size of the history of abortion or perinatal loss (POR: 3.57, CI: 1.44, 8.81). In this case, a high level of heterogeneity was observed $\left(\mathrm{I}^{2}\right.$ : 98.32 , Q:
59.54, df: $1, \mathrm{P}<0.001)$. In subgroup analysis, a high level of heterogeneity in West African studies ( $\mathrm{I}^{2}:$ 98.32, Q: 59.54, df: $1, P<0.001)$. Both community $\left(\mathrm{I}^{2}: 72.67, \mathrm{Q}\right.$ : 7.317, df: $2, P<0.026)$ and cohort studies $\left(\mathrm{I}^{2}: 80.48, \mathrm{Q}\right.$ : 5.12, df: $1, P<0.024)$ showed a moderate level of heterogeneity. However, its heterogeneity was not evident in total studies by region (Q: 0.003 , df: $1, P>0.957)$. It reduced to mild level by setting (Q: 4.58 , df: $2, P>0.101)$ and design (Q: 5.03, df: 2, $P>0.081$ ).

\section{Multiple gestation and perinatal mortality}

Five studies [32, 33, 38, 40, 42] were included for this meta-analysis. The observed odds ratio of multiple

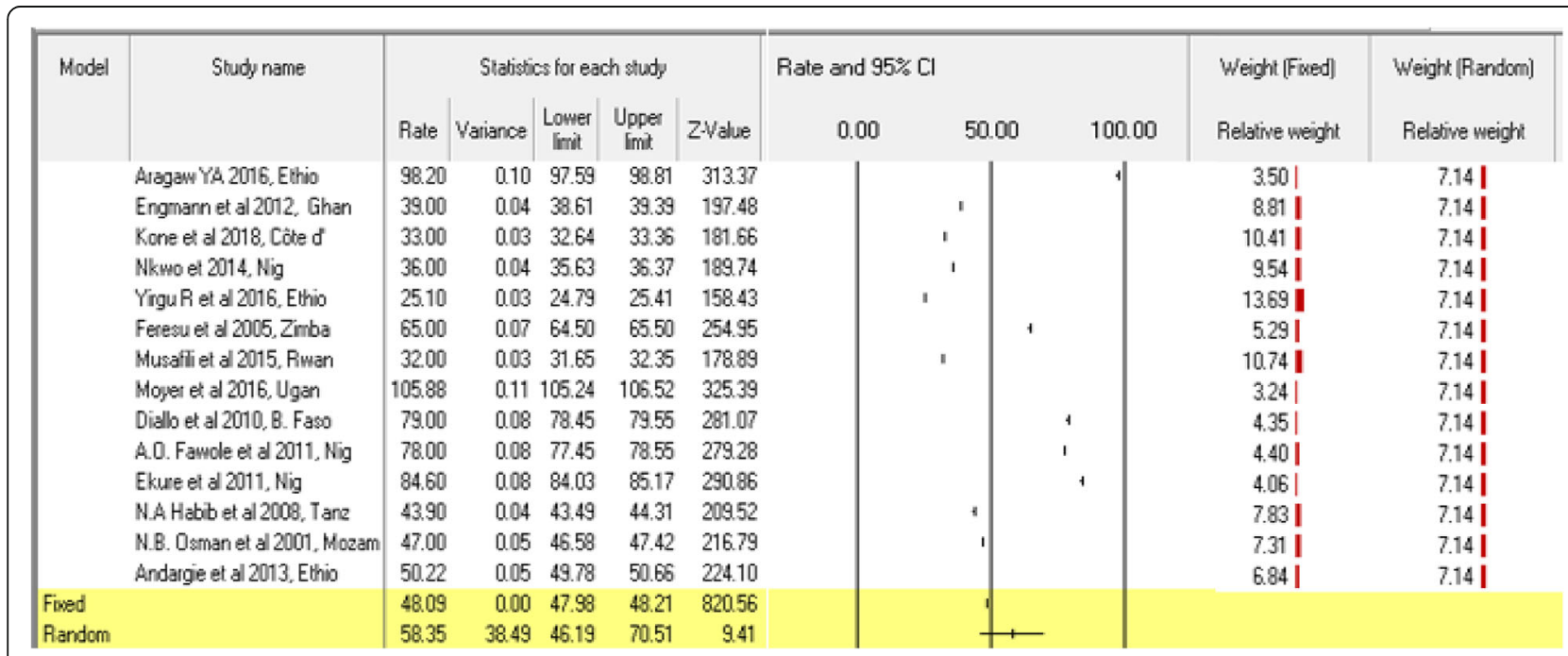

Fig. 2 Forest plot of perinatal mortality rate in Sub-Saharan countries, 2000-2019 GC 
Table 3 Subgroup analysis of perinatal mortality rate by region, study setting and design in Sub-Saharan countries, 2000-2019 GC

\begin{tabular}{|c|c|c|c|c|c|c|c|}
\hline \multirow{2}{*}{$\begin{array}{l}\text { Sub } \\
\text { group }\end{array}$} & \multirow{2}{*}{$\begin{array}{l}\text { Number } \\
\text { of studies }\end{array}$} & \multirow{2}{*}{$\begin{array}{l}\text { PMR } \\
(95 \% \mathrm{Cl})\end{array}$} & \multirow{2}{*}{$\begin{array}{l}\text { Standard } \\
\text { error }\end{array}$} & \multirow{2}{*}{$\begin{array}{l}\text { P-value } \\
\text { (P) }\end{array}$} & \multicolumn{3}{|c|}{ Extent of heterogeneity } \\
\hline & & & & & $\overline{1^{2}}$ & Q- stat & P-value (P) \\
\hline \multicolumn{8}{|l|}{ Region } \\
\hline E. Africa & 5 & $49.88(28.60,71.18)$ & 10.86 & $<0.0001$ & 99.99 & 47,751 & $<0.0001$ \\
\hline S. Africa & 2 & $56.00(22.33,89.67)$ & 17.18 & $<0.001$ & 99.96 & 2893 & $<0.0001$ \\
\hline W. Africa & 7 & $65.07(47.07,83.07)$ & 9.18 & $<0.0001$ & 99.99 & 79,902 & $<0.0001$ \\
\hline \multicolumn{8}{|l|}{ Setting } \\
\hline $\mathrm{CB}$ & 5 & $58.64(37.22,80.06)$ & 10.93 & $<0.0001$ & 99.99 & 70,302 & $<0.0001$ \\
\hline $\mathrm{FB}$ & 7 & $64.09(46.00,82.20)$ & 9.24 & $<0.0001$ & 99.99 & 58,306 & $<0.0001$ \\
\hline PB & 2 & $37.50(3.63,71.36)$ & 17.28 & $<0.03$ & 99.17 & 120 & $<0.0001$ \\
\hline \multicolumn{8}{|l|}{ Design } \\
\hline CS & 8 & $68.82(53.83,83.81)$ & 7.65 & $<0.0001$ & 99.99 & 79,476 & $<0.0001$ \\
\hline $\mathrm{CC}$ & 2 & $28.55(-1.43,58.53)$ & 15.30 & $>0.062$ & 99.88 & 834 & $<0.0001$ \\
\hline Co & 4 & $52.30(31.10,73.50)$ & 10.82 & $<0.0001$ & 99.98 & 19,084 & $<0.0001$ \\
\hline
\end{tabular}

gestations (twin and more) for the risk of perinatal mortality was 3.85 (CI: 2.60, 5.71, $P<0.001$ ) as compared to mothers with a singleton pregnancy (Table 8 ). Two studies were slimmed to estimate the adjusted effect size of multiple gestation for perinatal mortality (POR: 2.97, CI: 1.20, 4.43). There was a high level of heterogeneity in the region $\left(\mathrm{I}^{2}: 77.25\right.$, Q: 17.58 , df: 4 , $p<0.001)$. This determinant was highly heterogeneous in East Africa studies ( $\mathrm{I}^{2}:$ 85.51, Q: 6.90, df: 1 , $P<0.009)$. There were high $\left(\mathrm{I}^{2}: 91.90, \mathrm{Q}: 12.35\right.$, df: 1 , $\mathrm{P}<0.001)$ and moderate $\left(\mathrm{I}^{2}: 48.34, \mathrm{Q}: 1.94\right.$, df: $P>$ $0.16)$ level of heterogeneity in facility and community based studies respectively. Similarly, there were high $\left(\mathrm{I}^{2}:\right.$ 85.84, Q: 14.12, df: $\left.2, \mathrm{P}<0.001\right)$ and moderate $\left(\mathrm{I}^{2}:\right.$ 48.34, Q: 1.94 , df: $\left.1, \mathrm{P}>0.16\right)$ level of heterogeneity in cross section and cohort studies respectively. However, heterogeneity was not evident in total studies by region $(\mathrm{Q}: 0.39$, df: $2, P>0.822)$, setting $(\mathrm{Q}$ : 0.28 , df: $2, P>0.870)$ and design (Q: 0.39 , df: $1, P>$ $0.532)$.

\section{Preterm birth and perinatal mortality}

Nine primary studies $[28,30,31,34,37,40,41,43,46]$ were included. The observed odds ratio of preterm

\begin{tabular}{|c|c|c|c|c|c|c|c|c|}
\hline \multirow[t]{2}{*}{ Model } & \multirow[t]{2}{*}{ Study name } & \multicolumn{4}{|c|}{ Statistics with study removed } & \multicolumn{3}{|c|}{ Role (95\% Cl) with study removed } \\
\hline & & Point & Lower limit & Upper limit & ZValue & 0.00 & 50,00 & 10000 \\
\hline & Aragaw YA 2016, Ethio & 53.43 & 42.96 & 63.89 & 10.01 & & & \\
\hline & Engmann et al 2012. Ghan & 58.81 & 46.28 & 71.34 & 9.20 & & +1 & \\
\hline & Kone et al 2018 . Cóte d' & 59.36 & 47.16 & 71.55 & 9.54 & & & \\
\hline & Nkwo et 2014. Nig & 59.08 & 46.68 & 71.49 & 9.34 & & + & \\
\hline & Feresu et al 2005 , Zimba & 56.45 & 44.25 & 68.64 & 9.07 & & + & \\
\hline & Musafili et al 2015, Riwan & 59.45 & 47.35 & 71.54 & 9.63 & & 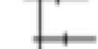 & \\
\hline & Diallo et al 2010, B. Faso & 55.17 & 43.61 & 66.74 & 9.35 & & 1 & \\
\hline & A.D. Fanole et al 2011, Nig & 55.26 & 43.65 & 66.88 & 9.32 & & 1, & \\
\hline & Ekure et al 2011. Nig & 54.66 & 43.39 & 65.94 & 9.50 & & i- & \\
\hline & N.A. Habib et al 2008, Tanz & 58.36 & 45.74 & 70.99 & 9.06 & & 4 & \\
\hline & N.B. Osman et al 2001, Mozam & 58.08 & 45.46 & 70.71 & 9.02 & & + & \\
\hline & Andargie et al 2013, Ethio & 57.79 & 45.19 & 70.39 & 899 & & 7 & \\
\hline Riandom & & 57.16 & 45.67 & 68.65 & 9.75 & & 7 & \\
\hline
\end{tabular}

Fig. 3 Forest plot of sensitivity analysis when one study of perinatal mortality revomed from Meta-Analysis in Sub-Saharan countries, 2000-2019 GC 
Table 4 High resolution plot of the odds of low birth weight for perinatal mortality rate in Sub-Saharan Countries, 2000-2019 GC

\begin{tabular}{|c|c|c|c|c|c|c|}
\hline \multirow[t]{2}{*}{ Study name } & \multirow[t]{2}{*}{ Comparison } & \multicolumn{5}{|c|}{$\underline{\text { Statistics for each study }}$} \\
\hline & & $\begin{array}{l}\text { Odds } \\
\text { ratio }\end{array}$ & $\begin{array}{c}\text { Lower } \\
\text { limit }\end{array}$ & $\begin{array}{c}\text { Upper } \\
\text { limit }\end{array}$ & Z-value & $\mathrm{p}$-Value \\
\hline Getiye et al 2017, Ethiopia & Low birth weight & 16.450 & 9.573 & 28.268 & 10.138 & 0.000 \\
\hline Aragaw Ya et al 2016, Ethiopia & Low birth weight & 5.030 & 1.658 & 15.259 & 2.853 & 0.004 \\
\hline Goba et al 2018, Ethiopia & Low birth weight & 11.500 & 3.141 & 42.105 & 3.688 & 0.000 \\
\hline Tachiweyika et 2011, Zimbabwe & Low birth weight & 9.450 & 3.910 & 22.840 & 4.988 & 0.000 \\
\hline Yego et al 2014, Kenya & Low birth weight & 6.600 & 3.801 & 11.462 & 6.701 & 0.000 \\
\hline Ekure et al 2011, Nigeria & Low birth weight & 9.020 & 4.908 & 16.575 & 7.084 & 0.000 \\
\hline N.B. Osman et al 2001, Mozambique & Low birth weight & 4.200 & 1.489 & 11.849 & 2.712 & 0.007 \\
\hline & & 8.693 & 6.038 & 12.514 & 11.632 & 0.000 \\
\hline
\end{tabular}

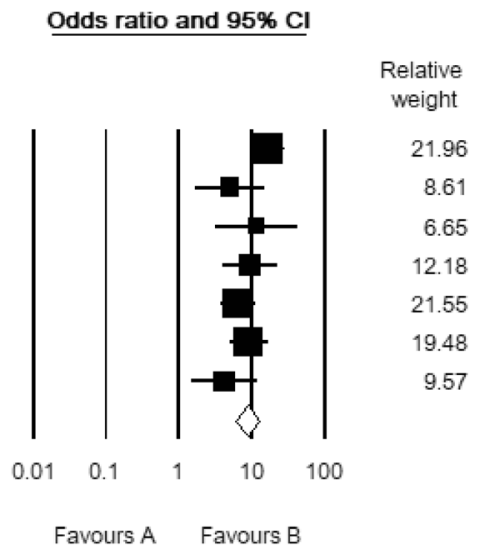

Favours A Favours B

babies whose gestational age was less than 37 completed weeks was 4.42 (CI: 2.83, 6.88, $p<0.001$ ) for the risk of perinatal mortality as compared to term babies (Table 9).

Two studies were trimmed to estimate the adjusted effect size of preterm birth on perinatal mortality (POR: 3.31, CI: 2.10, 5.22). There was a moderate level of heterogeneity ( $\left.\mathrm{I}^{2}: 69.43, \mathrm{Q}: 26.172 \mathrm{df:} 8, P<0.001\right)$. In sub group analysis, a moderate level of heterogeneity in East Africa was observed ( $\mathrm{I}^{2}: 71.08, \mathrm{Q}: 13.83$ df: $\left.4, P<0.008\right)$. There was a moderate level of heterogeneity in facility studies $\left(\mathrm{I}^{2}: 77.72\right.$, Q: 17.95 , df: $\left.4, \mathrm{P}<0.001\right)$ and crosssectional study design $\left(\mathrm{I}^{2}:\right.$ 72.76, Q: 11.013, df: 3, $P<$ 0.012). However, heterogeneity was not evident in total studies by region (Q: 3.69 , df: $2, P>0.158)$, setting
(Q: 1.08, df: $2, P>0.582$ ) and design (Q: 4.13, df: $2, P>$ $0.127)$.

\section{Birth interval and perinatal mortality}

Four primary studies [28, 31-33] were included. The observed odds ratio of birth interval was 2.24 (CI: 1.53, $3.29, P<0.0001)$ for the risk of perinatal mortality as compared to babies born where birth interval was two or more years (Table 10). Two studies were trimmed to estimate the adjusted effect size of short birth interval ( $<2$ years) for the risk of perinatal mortality (POR: 1.75, CI: 1.18, 2.60). There were moderate level of heterogeneity ( $\mathrm{I}^{2}: 50.62$, Q: $\left.6.07 \mathrm{df}: 3, P>0.108\right)$. In sub group analysis, heterogeneity was not evident in East Africa $\left(\mathrm{I}^{2}: 0\right.$, Q: 1.52 , df: $2, P>0.468)$. Both facility setting studies and

Table 5 High resolution plot for the odds of primiparity for perinatal mortality rate in Sub-Saharan Countries, 2000-2019 GC

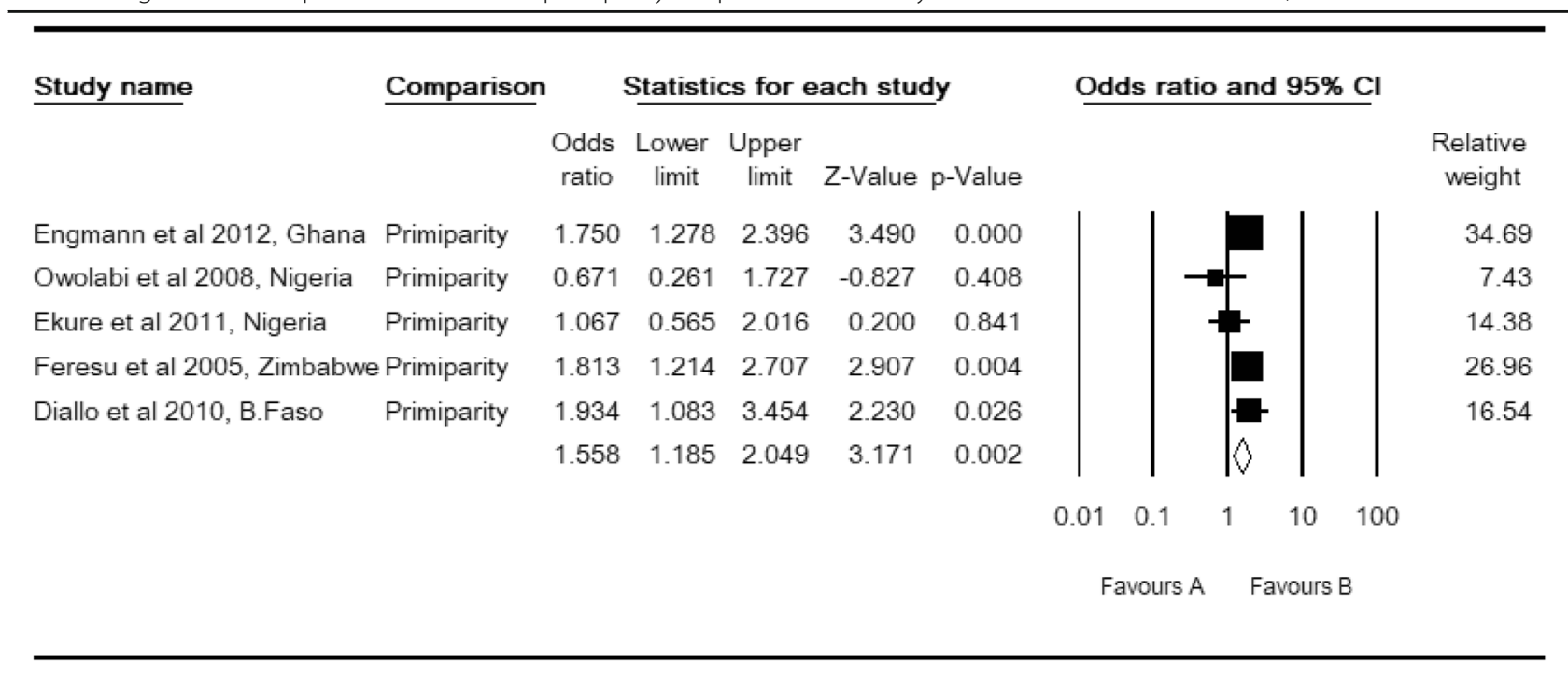


Table 6 High resolution plot of the odds with No ANC visits for perinatal mortality rate in Sub-Saharan Countries, 2000-2019 GC

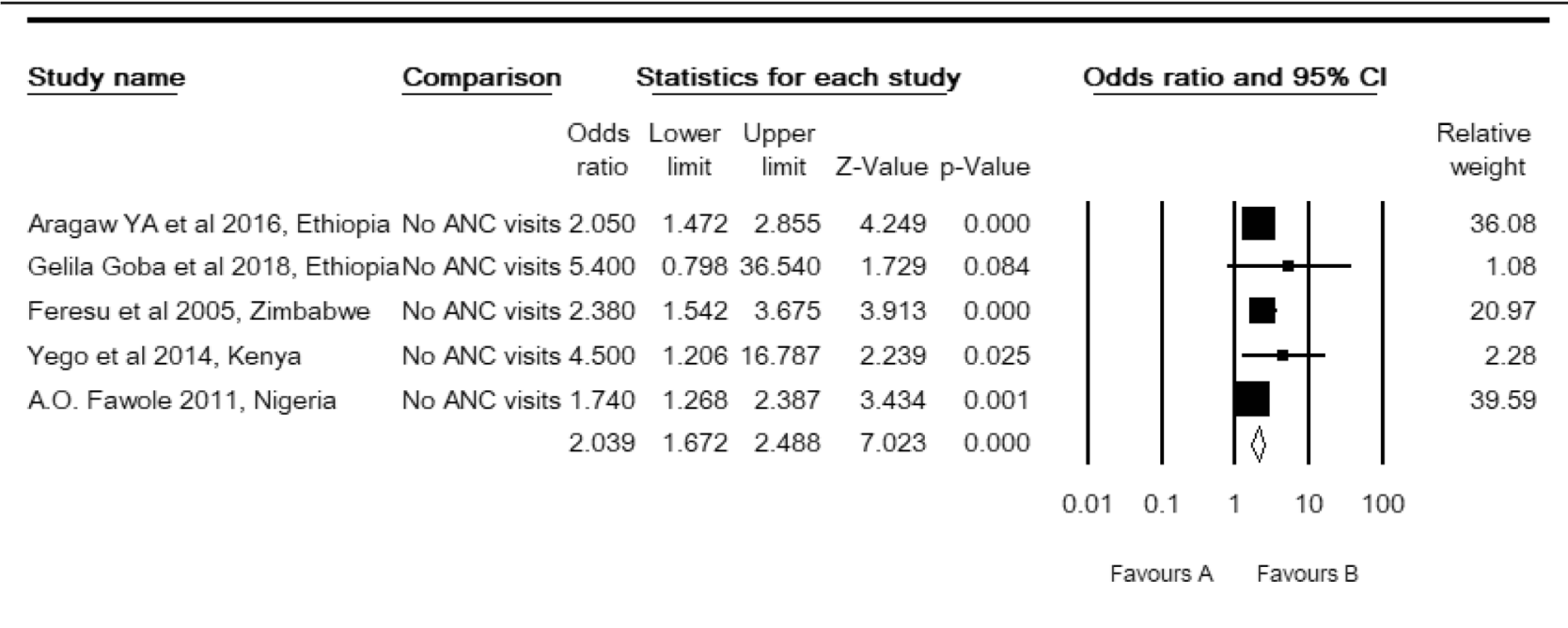

NB: Favors 'A': At least one ANC visit, Favors 'B': with No ANC visits

case control study designs showed a mild and equal level of heterogeneity $\left(\mathrm{I}^{2}: 28.80\right.$, Q: 1.4 , df: $\left.1, P>0.236\right)$. But, there was no evidence of heterogeneity between total studies by region (Q: 4.56 , df: $2, P<0.033$ ) or by study setting and design with equal statistical values $(\mathrm{Q}: 1.79$, df: $2, P>0.408)$.

\section{Mode of deliveries and perinatal mortality}

Among four included studies [30, 34, 39, 41], there were seven statistical associations from five determinants; two instrumental, one emergence Cesarean Section, one elective Cesarean Section, two breech, and one shoulder delivery. One included study has more than one statistical association making a total of seven independent odds ratio. The odds ratio of these determinants among mothers who gave birth through nonspontaneous vaginal delivery was 2.94 (CI: $0.99,8.72$, $P>0.052)$ as compared to mothers who gave birth through spontaneous vaginal delivery (Table 11). Three studies were trimmed to estimate the adjusted effect size of non-spontaneous mode of delivery for perinatal mortality (POR: $1.20, \mathrm{CI}: 0.39,3.68)$. There was a high level of heterogeneity ( $\mathrm{I}^{2}: 95.40$, Q: 152.22 , df: $7, P<0.0001$ ). In sub group analysis by region, there was a moderate level of heterogeneity ( $\mathrm{I}^{2}: 50.62$, Q: $\left.6.07 \mathrm{df}: 3, P>0.108\right)$. There was a high level of heterogeneity in West Africa

Table 7 High resolution plot of the odds of history $(\mathrm{Hx})$ of perinatal loss for perinatal mortality rate in Sub-Saharan Countries, 20002019 GC

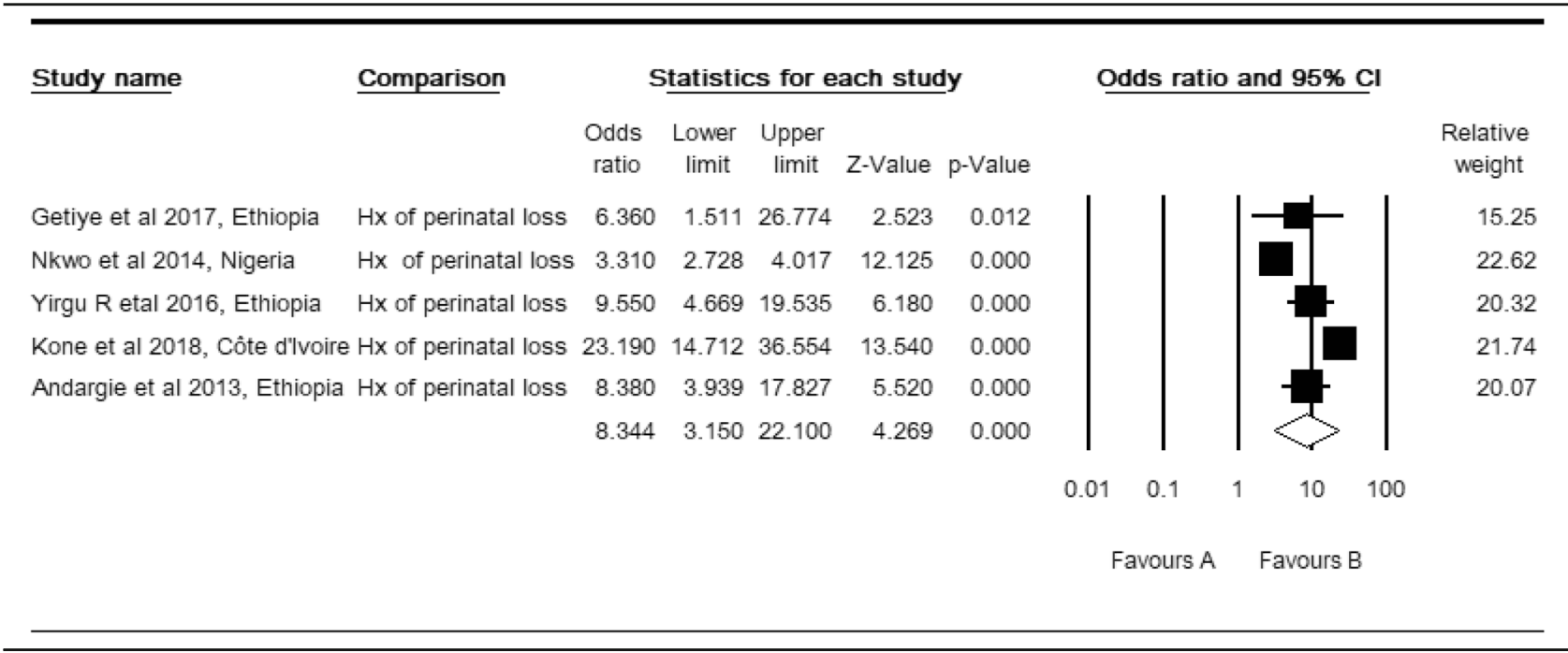


Table 8 High resolution plot of the odds of multiple gestation as a determinant for perinatal mortality rate in Sub-Saharan Countries, 2000-2019 GC

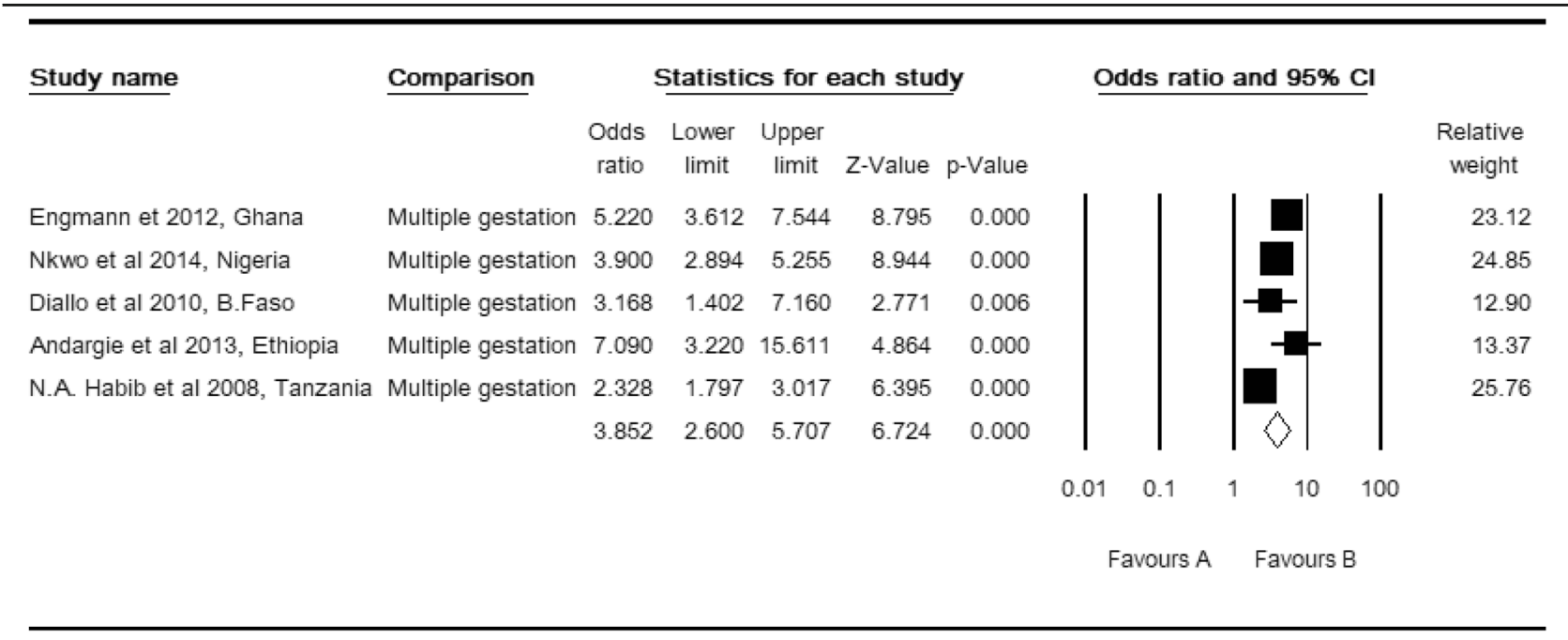

NB: Favors 'A': No nultiple gestation, 'B': multiple gestation

( $\mathrm{I}^{2}:$ 93.23, Q: 44.32, df: 3, $\left.\mathrm{P}<0.0001\right)$, in facility studies $\left(\mathrm{I}^{2}:\right.$ 96.36, $\mathrm{Q}: 137.56$, df: $\left.5, \mathrm{P}<0.0001\right)$ and crosssectional study designs ( $\mathrm{I}^{2}: 96.36$, Q: 137.56 , df: $5, \mathrm{P}<$ $0.0001)$. But, it was not evident in total studies by region (Q: 1.89 , df: $3, P>0.595)$, study setting and design (Q: 1.053, df: $1, P>0.305)$.

\section{Discussion}

In this systematic review and meta-analysis, the overall observed perinatal mortality rate was 58.35 (95\% CI: 46.
$19,70.51, P<0.001)$ per 1000 total births in the randomeffect analysis. Four fitted values made the adjusted effect size of PMRs to be 42.95 (95\% CI: 29.21, 56.70). We also conducted subgroup analyses to compare the difference between effect sizes in different groups. In this subgroup of meta-analysis, the PMRs were high in West Africa, 65.07 (95\% CI: 47.07, 83.07), in a facility setting, 64.09 (95\% CI: 46.00, 82.20) and as reported in studies using cross-sectional study design, 68.82 (95\% CI: 53.83, 83.81).

Table 9 High resolution plot of the odds of preterm birth as a determinant for perinatal mortality rate in Sub-Saharan Countries, 2000-2019 GC

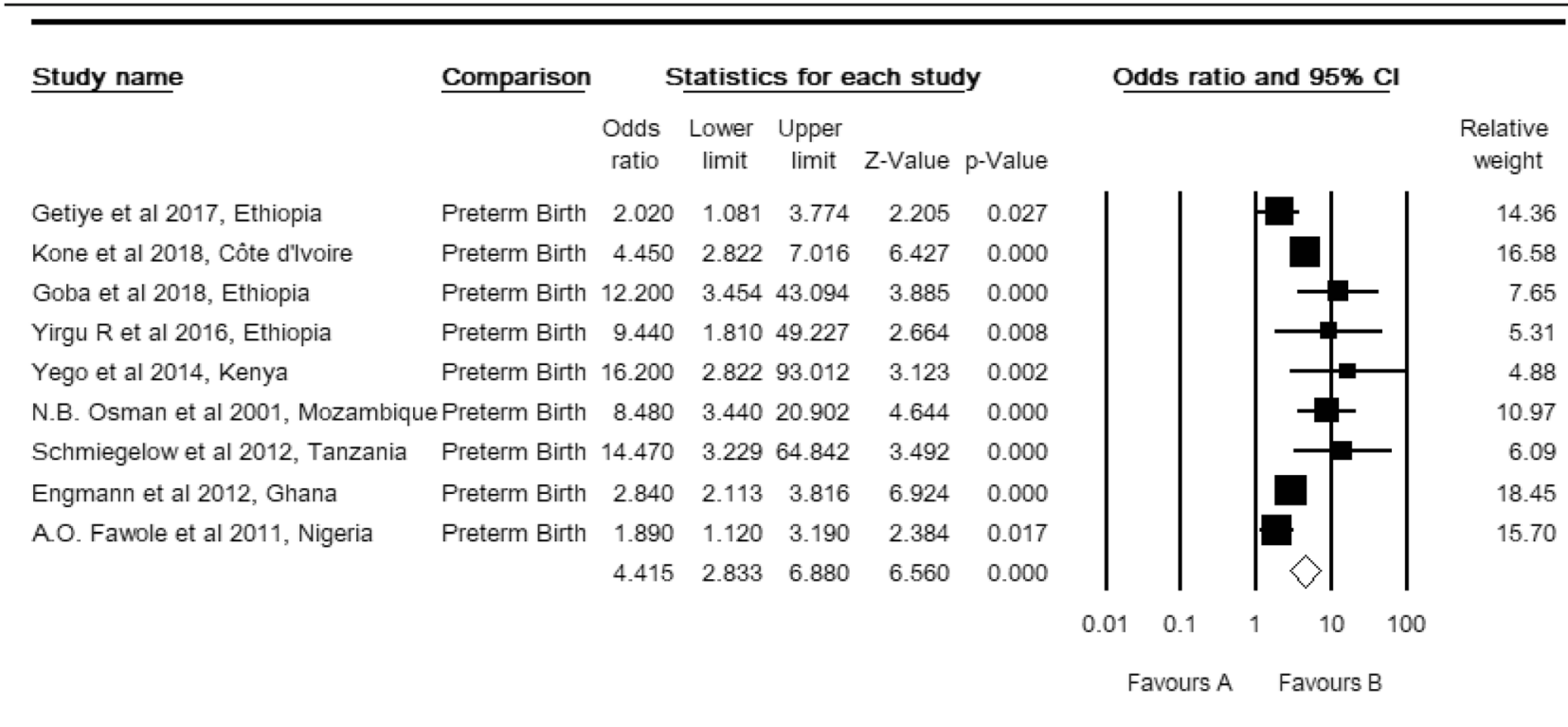


Table 10 High resolution plot of the odds of short birth interval as a determinant for perinatal mortality rate in Sub-Saharan Countries, 2000-2019 GC

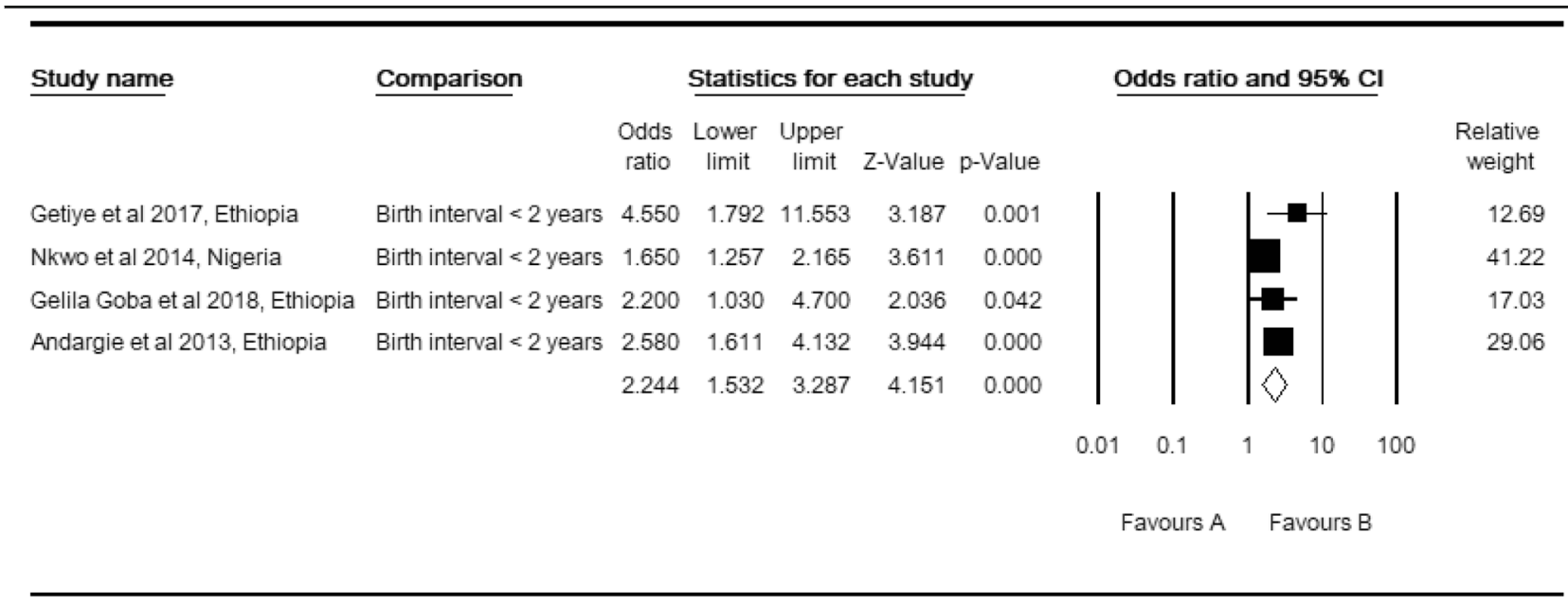

NB: Favors 'A': Normal birth interval, Favors 'B': Short birth interval (less than two years)

Heterogeneity and publication bias in perinatal mortality There was heterogeneity of studies in reported PMRs and their determinants. Its extent was high in the study region ( $\mathrm{I}^{2}$ : 99.99, df: 13, Q: $\left.143573.67, P<0.0001\right)$. Both the Isquared $\left(\mathrm{I}^{2}\right)$ and Cochran $(\mathrm{Q})$ tests showed high levels of heterogeneity in each study by region, study setting, and study design with a strong statistical association $(P<$ $0.001)$. However, it was not evident in total studies by region (Q: 1.16, df: 2, $P>0.56$ ), setting (Q: 1.84 , df: $2, P>$ 0.398 ) and design (Q: 5.982, df: $2, P>0.05)$ using subgroup analyses. The possible reason for this bias could be the inclination of researchers in reporting findings only achieving statistical significance. It might lead to inaccurate conclusions in a meta-analysis that could seriously impact the clinical practices.

Begg and Mazumdar's test estimated the rank correlation (Kendall's) between the standardized Effect Sizes (ES) of PMRs and variances or standard errors (SE) of these effects. It may be interpreted much the same way as any correlation, with a value of zero indicating no relationship between effect size and precision. If the value (P-Q) deviates from zero, it subjectively informs us the

Table 11 High resolution plot of the odds of non-spontaneous vaginal delivery for perinatal mortality rate in Sub-Saharan Countries, 2000-2019 GC

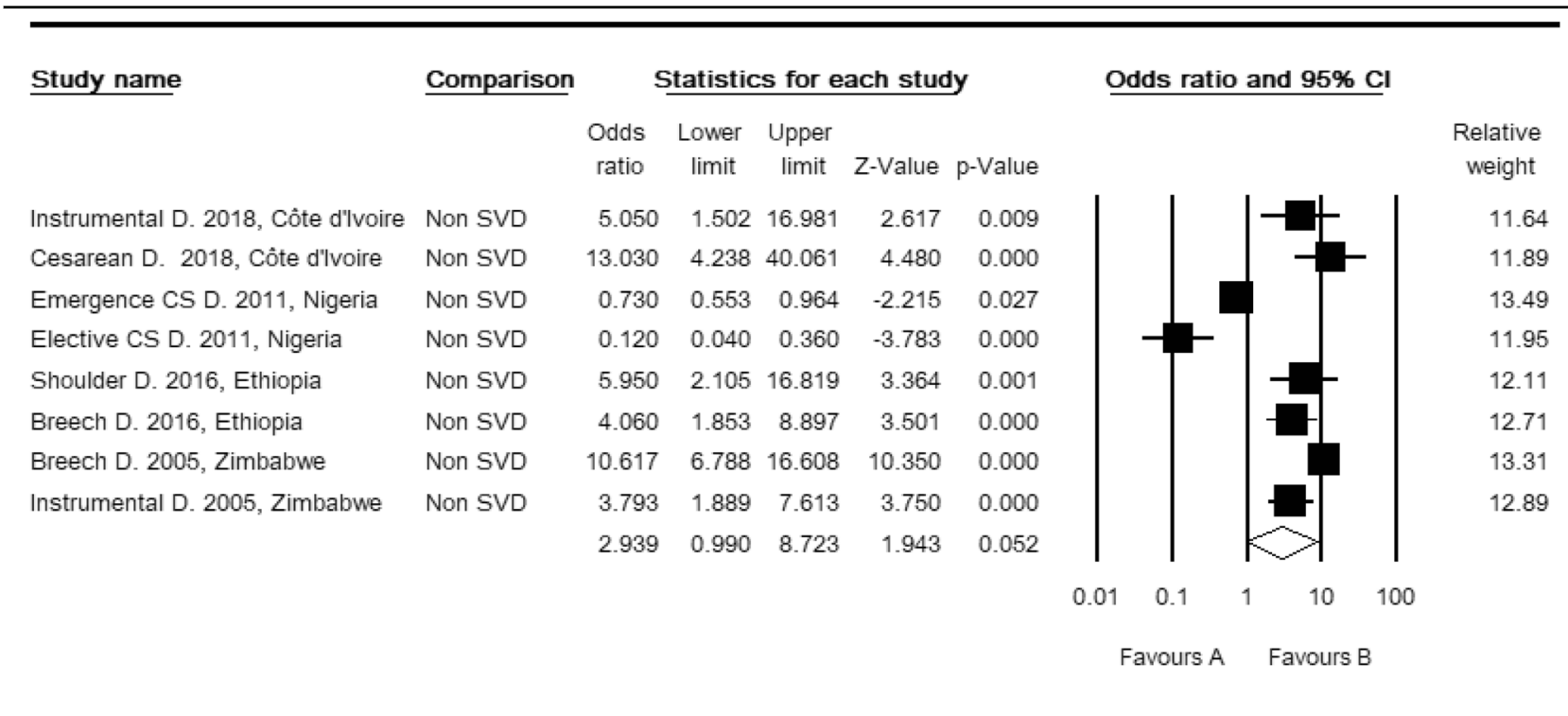

NB: Favors 'A': Spontaneous vaginal delivery, Favors 'B': Non-spontanous delivery (Instrumental, Cesarean, Emergence Cesarean, Elective Cesarean, Shoulder, and breech delivery). 
presence of a relationship. An asymmetry of funnel plot exists when large standard errors are associated with larger effect sizes. The possible causes of this relationship may be the presence of publication bias $[16,19-22,47]$. The size of the intercept provides a measure of asymmetry - the larger the deviation from zero, the greater the asymmetry. A positive intercept indicates that the effect estimated from the smaller studies is greater than the effect estimated from larger studies. Conversely, a negative intercept indicates that the effect estimated from the smaller studies is less than the effect estimated from larger studies $[16,19,22]$.

In this meta-analysis of the PMRs, Begg and Mazumdar rank correlation revealed a Kendall's $S$ statistic was deviated from zero $(\mathrm{P}-\mathrm{Q}=91)$, and Kendall's Tau $(\tau)$ without continuity correction $=1.00 \quad(P<0.0001)$. In addition, the Egger's linear regression intercept (469.94, $95 \%$ CI: 441.63, 498.25, $\mathrm{P}<0.0001)$ did not include zero indicating the presence of a relationship. It implies that there was evidence of heterogeneity and publication bias in Sub-Saharan studies of perinatal mortality. However, it was not evident in subgroup analysis using region, setting, and study design. In this meta-analysis, missed studies were fitted on the left side of the mean value of the effect sizes during analysis athough it has no effect in the random effect model. However, smaller effects size in the left direction is more likely favored in the publication process and studies with large effects size may be suppressed to the right from the median line of the funnel plot $[16,19,27]$.

In this study, both Begg's rank correlation and Egger's regression tests confirmed the presence of a relationship between the standardized effect sizes and the standard error of these effects. Publication bias might be the cause of the relationship. In this analysis of PMRs, the visual presentation of the funnel plot was asymmetric and skewed in a positive direction. However, four studies were fitted in a negative direction to treat the asymmetry. This asymmetry might occur due to the existence of publication bias (Fig. 4).

\section{Determinants for perinatal mortality}

In this subcategory of meta-analysis, observed and adjusted values of low birth weight for the risk of perinatal mortality were equal and revealed that publication bias did not exist. Begg and Mazumdar rank correlation revealed a Kendall's S statistic was closed to zero ( $\mathrm{P}-\mathrm{Q}=-$ $1)$, and Kendall's Tau $(\tau)$ without continuity correction = $-0.048(P>0.881)$. The Egger's regression test did also include zero (Intercept: $-1.48,95 \%$ CI: $-5.373,2.421$, $P>0.375)$. Therefore, both methods revealed no relationship between the standardized ESs and SE of these effects. Similarly, the adjusted values for primiparity was equal to the observed values to estimate the final effect sizes. Begg and Mazumdar rank correlation revealed a Kendall's Significance (S) statistic was deviated from zero $(\mathrm{P}-\mathrm{Q}=-10)$, and Kendall's Tau ( $\mathrm{\tau})$ without continuity correction $=-1.00 \quad(P<0.014)$. However, the Egger's regression test revealed no relationship between the standardized ESs and SE of these effect sizes because the intercept did include zero (Intercept: -2.42 , 95\% CI: 6.01, 1.16, $P>0.12$ ).

Regarding the ANC visits, two studies were slimmed to estimate the effect sizes of no ANC visits for the risk of perinatal mortality. Begg and Mazumdar rank correlation revealed a Kendall's $S$ statistic was deviated from zero $(\mathrm{P}-\mathrm{Q}=8)$, and Kendall's Tau $(\tau)$ without continuity correction $=0.80(P<0.05)$. The Egger's regression did not include zero (Intercept: 1.57, 95\% CI: 0.05, 3.08, $p<$ 0.046). Therefore, both methods showed us the presence

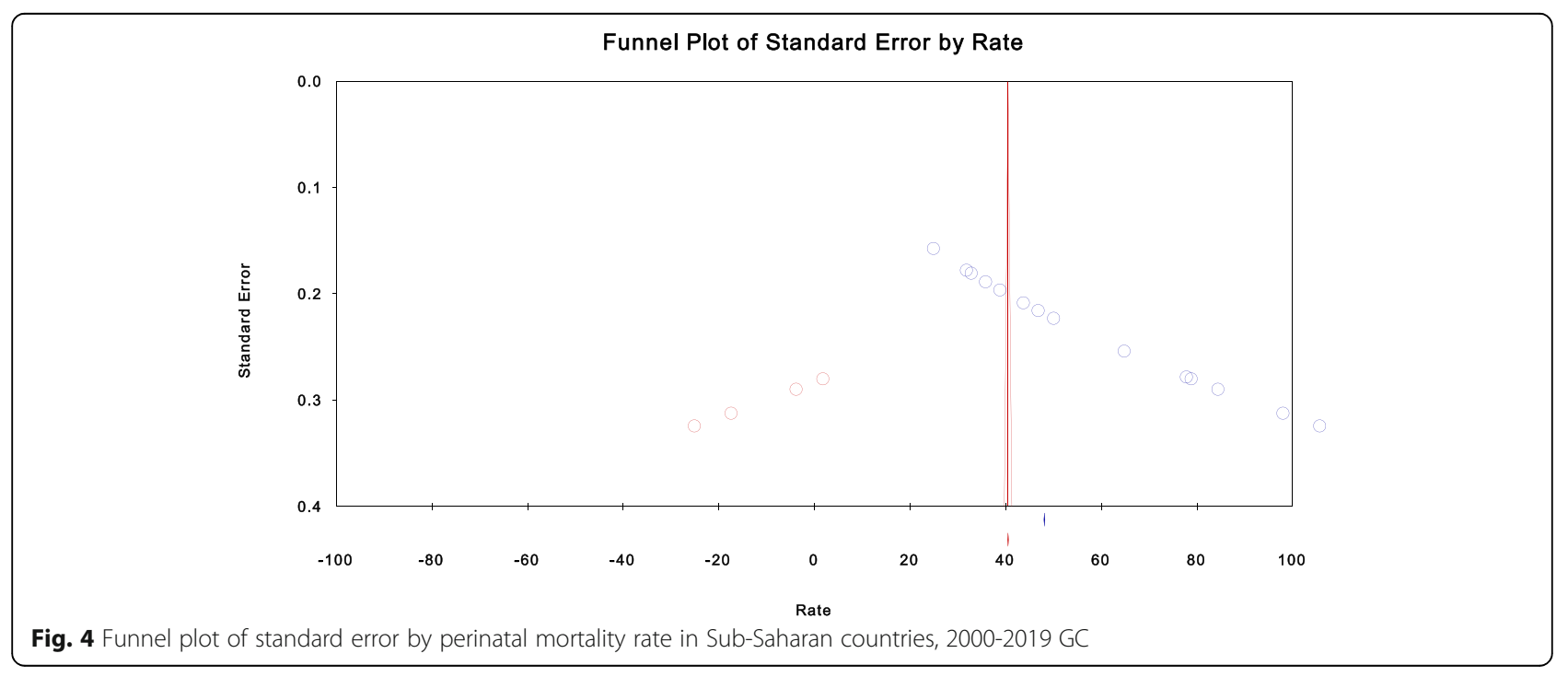


of relationships between the standardized ESs and SE of these effect sizes. Three studies were trimmed to estimate the effect size of abortion or perinatal loss as a risk factor for perinatal mortality. Begg and Mazumdar rank correlation revealed a Kendall's S statistic was closed to zero $(P-Q=-2)$, and Kendall's Tau ( $\tau$ ) without continuity correction $=-0.20(P>0.624)$. The Egger's regression did include zero (Intercept: 3.81, 95\% CI: $-5.05,12.68$, $p>0.265)$. Both methods revealed no relationship existed.

Regarding multiple gestation, two studies were slimmed, and Begg and Mazumdar rank correlation revealed a Kendall's $S$ statistic was closed to zero $(P-Q=2)$, and Kendall's Tau $(\tau)$ without continuity correction $=0.20(P>0.624)$. The Egger's regression intercept did include zero (Intercept: $2.39,95 \%$ CI: $-5.09,9.88, P>0.384)$. Therefore, both methods showed us the absence of a relationship. Likewise, three studies were trimmed to estimate the adjusted effect size of preterm birth on perinatal mortality. Begg and Mazumdar rank correlation revealed a Kendall's S statistic was deviated from zero $(\mathrm{P}-\mathrm{Q}=8)$, and Kendall's Tau $(\tau)$ without continuity correction $=0.22(P>0.404)$. The Egger's regression intercept did not include zero (Intercept: 2.26, 95\% CI: 0.22, 4.30, $P<0.034$ ) and revealed the presence of a relationship. Publication bias might be the cause for this relationship.

Again, two studies were trimmed to estimate the size of the adjusted effect of birth interval less than two years for the risk factor of perinatal mortality. Begg and Mazumdar rank correlation revealed a Kendall's S statistic $(P-Q=4)$ was closed to zero, and Kendall's Tau ( $\tau$ ) without continuity correction $=0.67(P>0.174)$. The Egger's regression did include zero (Intercept: 2.41, 95\% CI: $-1.73,6.55, p>$ 0.129 ). Therefore, both methods revealed no relationship. Finally, three studies were trimmed to estimate the size of the adjusted effects of non-spontaneous vaginal delivery for the risk of perinatal mortality. Begg and Mazumdar rank correlation revealed a Kendall's $S$ statistic was zero as expected $(\mathrm{P}-\mathrm{Q}=0)$, and Kendall's Tau $(\tau)$ without continuity correction $=0.00(P=1.000)$. The Egger's regression did include zero as expected (Intercept: 3.34, 95\% CI: - 4.54, 11.22, $P>0.3397$ ). Consequently, both methods showed that a relationship did not exist.

In general, studies would differ in design and conduct as well as in participants, interventions, exposures, or outcomes. It might be the possible reason in which most heterogeneity tests confirmed the presence of variation in effect sizes in this meta-analysis. It would also be the existence of the different studies caused by a systematic difference between the included studies for this review. Statistical heterogeneity exists when the effects differ between studies $[47,48]$. A small number of included studies have a precision close to zero due to their large size effects. In this case, the funnel plot is supposed to be asymmetrical, and publication bias appears. For this purpose, we selected the trim-and-fill method to detect the significance of publication bias because we only reviewed twenty-one studies. It also provides bias-adjusted results for small studies [49-51] considering extracting unpublished studies is not achievable. This method estimates

\section{Funnel Plot of Standard Error by Log odds ratio}

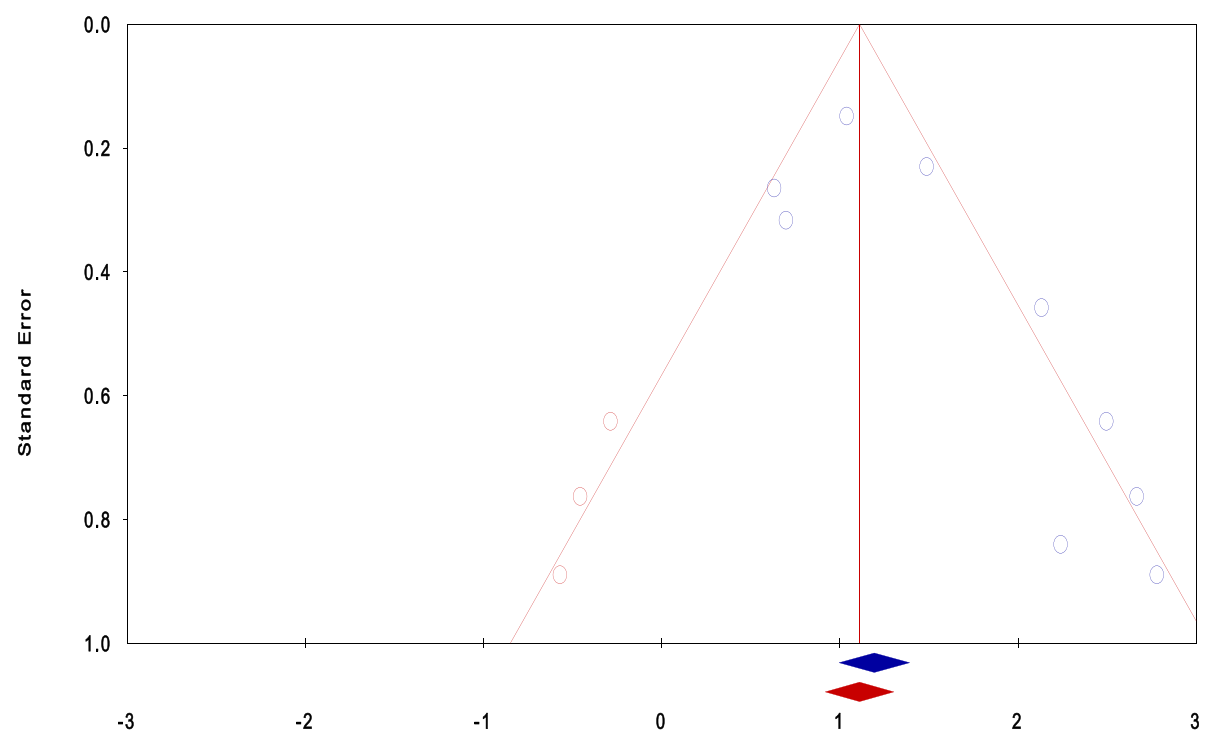

Log odds ratio

Fig. 5 Funnel plot of standard error by log odds ratio for detecting publication bias and heterogeneity of preterm birth on perinatal mortality 
the size of the adjusted effects only by approximating statistically imputed missing values [27].

In this regression analysis, a positive intercept implies a bias towards the right side of the funnel plot, and the missing studies are in the negative direction. In contrast, a negative intercept indicates a bias toward the left side, and the missing values are likely in the right direction [22]. In this meta-analysis, the results obtained from small studies scattered widely at the bottom of the graph of the funnel plot. The spread was narrow at the top of the funnel plot of studies with adequate sample size [52]. In primiparity, the funnel plot was resembled a symmetrical graph showing the absence of publication bias. However, the results of most determinants for perinatal mortality were asymmetrically skewed to the positive direction indicating the presence of publication bias. The adjusted result of preterm birth was skewed in a positive direction, and some studies were slimmed to estimate the size of the adjusted effects. The possible reason might be missing studies suppressed by publication bias in a meta-analysis (Fig. 5).

In this study, we mostly rejected null hypotheses, and there were moderate and high levels of heterogeneity in this meta-analysis. We believe that all effect sizes in the sample of included studies might not vary only because of sampling error. As a researcher, we also anticipate the presence of unpublished studies related to perinatal mortality. It helps us think about the existence of systematic study level variability and the presence of true heterogeneity. For these reasons, selecting the randomeffects model was appropriate for this meta-analysis. However, systematic review methods are subjective regarding the selection of studies to include or exclude from this review. Studies that were primarily diverse in different circumstances may lead this meta-analysis to be inaccurate. It might obscure the genuine differences in the overall mean effects of meta-analysis in the random-effect analysis. Once decisions and clinical judgments for combining individual studies are inevitably and subjectively included, there are not solutions for adjustment or amendment in statistics. It produces a wrong result interpreted as having more credibility for decision making and inappropriate summaries [51].

\section{Conclusion}

In this review and meta-analaysis, the observed and adjusted PMR was 58.35 and 42.95 respectively per 1000 deliveries. High level of heterogeneity was evident in total studies of perinatal mortality and its determinants $\left(\mathrm{I}^{2}>99\right.$ perecent). Only low birth weight and primiparity were not approximated by statistically imputed missing studies in estimating the final effects sizes. Most determinants were presented with a positive intercept of regression and a positive correlation indicating the presence of heterogeneity and publication bias. This informs us publications existed which might be a major threat to the validity of the conclusions in this study. However, less heterogeneity was observed in subgroup analysis. Therefore, engaging in systematic review and meta-analysis would potentially improve underrepresented strategies and actions by informing policy makers and program implementers for minimizing the existing socioeconomic inequalities between regions and nations. Finally, it is recommended to improve supply, demand, equity, and quality of services in countries having high perinatal mortality.

\section{Abbreviations \\ ANC: Antenatal Care; Cl: Confidence Intervali"; CMA: Comprehensive Meta- Analysis; DHS: Demography and Health Survey; ENAP: Early neonatal action plan; ES: Effects size; GC: Gregorian calendar; JBI: Joanna Briggs Institute; LBW: Low Birth Weight; LMICS: Low and Middle-Income Countries; PMRs: Perinatal mortality rates; POR: Pooled Odds Ratio; PRISMA: Preferred reporting items for systematic reviews and meta-analyses; SE: Standard Error; STROBE: Strengthening the Reporting of Observational Studies in Epidemiology; WHO: World Health Organization}

\section{Acknowledgments \\ We are very grateful to acknowledge the authors of the research articles included in this review. Our heartfelt gratitude extends to Haramaya University for facilitating the review process. We would also like to appreciate staff and Ph.D. students at the School of Public Health, Haramaya University, for their constructive comments. We need to acknowledge Agezegn Assegid and Shimelis Biru who involved in the independent screening of articles and assisted us in reviewing and commenting on the earlier drafts of the manuscripts. All the authors read and approved the final version of the manuscript to be sent for publication.}

\section{Availability of dataset and materials}

The annexed tables are available at the end of the manuscript for anyone interested. The remaining datasets that illustrate the findings of this review and analysis could be available as per the request.

\section{Authors' contributions}

Dawit Tiruneh initiated the conception of this review, conducted a literature review, assessed the studies and carried out the systematic review and metaanalysis, wrote the the manuscript. Nega Assefa supervised the overall process of the review with constructive comments starting from the conception to comments up to the preparation of the final manuscript. Bezatu Mengiste directed the design, quality assessment and supervised the review and commented on the final drafts of the manuscripts. All authors have read and approved the final manuscript to be sent for publication.

Ethics approval and consent to participate Not applicable.

Consent for publication

Not applicable.

\section{Competing interests}

We declare that conflict of interest for this review will never exist.

\section{Author details}

'Department of Midwifery, College of Health Sciences, Debre Tabor University, National State of Amhara, Debre Tabor Town, South Gondar Province, Ethiopia. ${ }^{2}$ Department of Nursing, College of Health and Medical Science, Haramaya University, Harar, Ethiopia. ${ }^{3}$ Department of Environmental Science, College of Health and Medical Science, Haramaya University, Harar, Ethiopia. 
Received: 6 December 2019 Accepted: 17 November 2020 Published online: 01 January 2021

\section{References}

1. Lawrence D, Hancock KJ, Kisely S. The gap in life expectancy from preventable physical illness in psychiatric patients in Western Australia: retrospective analysis of population based registers. BMJ. 2013;346:f2539.

2. IISD. UN Report on Newborn and Child Mortality Rates on the Rise. International institute for sustainable development. 2017.

3. WHO. World health statistics. 2014. ISBN 978924156471 7. Available https://apps.who.int/iris/bitstream/handle/10665/112738/9789240692671.

4. Graham WJ, Cairns J, Bhattacharya S, Bullough CHW, Quayyum Z, Rogo K. Maternal and perinatal conditions; disease control priorities in developing countries. In: The International Bank for Reconstruction and Development The World Bank. 2nd ed. New York: Oxford University Press; 2006.

5. Tachiweyika E, Gombe N, Shambira G, Chadambuka A, Mufuta T, Zizhou S. Determinants of perinatal mortality in Marondera district, Mashonaland East Province of Zimbabwe, 2009: a case control study. Pan Afr Med J. 2011:8:7. https://doi.org/10.4314/pamj.v8i1.71054.

6. Horton, Samarasekera. Stillbirths: ending an epidemic of grief. 2016 387(10018):515-6 https://doi.org/10.1016/S0140-6736(15)01276-3.

7. WHO. Classifying the causes of perinatal death. 2016;94:79 https://doi.org/ 10.2471/BLT.15.168047

8. Newman L, Baum F, Javanparast S, O'Rourke K, Carlon L. Addressing social determinants of health inequities through settings: a rapid review. Health Promot Int. 2015;30(suppl_2):ii126-43 https://doi.org/10.1093/heapro/dav054

9. Lawn JE, Blencowe H, Waiswa P, Amouzou A, Mathers C, Hogan D, Flenady V, Frøen JF, Qureshi ZU, Calderwood C, Shiekh S, Jassir FB, You D, McClure EM, Mathai M, Cousens S. Lancet series: ending preventable still births; Stillbirths: rates, risk factors, and acceleration towards 2030. 2016. https://doi. org/10.1016/S0140-6736(15)00837-5

10. WHO. Monitoring health for the SDGs. World Health Statistics. 2019. Accessed at https:/www.who.int/gho/publications/world_health_statistics/2019/en/.

11. Vandenbroucke JP, von Elm E, Altman DG, Gøtzsche PC, Mulrow CD, Pocock SJ, Poole C, Schlesselman JJ, Egger M. Strengthening the Reporting of Observational Studies in Epidemiology (STROBE): Explanation and elaboration. Int J Surg. 2014;12:1500e1524.

12. The Joanna Briggs Institute. Systematic Review; Protocol; Effectiveness; Qualitative; Economic; Mixed Methods Review and Methods; Joanna Briggs Institute Reviewers' Manual. 2014. edition / Supplement.

13. Moher D, Liberati A, Tetzlaff J, Altman DG, The PRISMA Group. Preferred Reporting Items for Systematic Reviews and MetaAnalyses: The PRISMA Statement. PLoS Med. 2009;6(7):e1000097 https://doi.org/10.1371/journal. pmed.1000097.

14. Tonya M. Esterhuizen, Lehana Thabane, Con: Meta-analysis: some key limitations and potential solutions. Nephrol Dial Transplant. 2016;31(6):882-5 https://doi.org/10.1093/ndt/gfw092.

15. Higgins JP, Thompson SG, Deeks JJ, Altman DG. Measuring inconsistency in meta-analyses. BMJ. 2003;327(7414):557-60 https://doi.org/10.1136/bmj.327. 7414.557.

16. Faris $H$, Jahrami A, BaHammam Z, Kalaji M, Madkour M. Hassanein, A systematic review, meta-analysis, and meta-regression of the impact of diurnal intermittent fasting during Ramadan on glucometabolic markers in healthy subjects. Diabetes Res Clin Pract. 2020; https://doi.org/10.1016/j. diabres.2020.108226.

17. Borenstein M, Hedges LV, Higgins JP, Rothstein HR. A basic introduction to fixed-effect and random-effects models for meta-analysis. Res Synth Methods. 2010;1(2):97-111 https://doi.org/10.1002/jrsm.12.

18. Borenstein $M$, Hedges LV, Higgins JPT, Rothstein HR. Introduction to metaanalysis. West Sussex: Wiley; 2009. ISBN: 978-0-470-05724-7.

19. StataCorp. Stata technical bulletin. A publication to promote communication among stata users, Texas A \&M university. 1998.

20. Begg CB, Mazumdar M. Operating characteristics of a rank correlation test for publication bias. Biometrics. 1994;50:1088-101 https://doi.org/10.2307/ 2533446.

21. Egger M, Davey SG, Schneider M, Minder C. Bias in meta-analysis detected by a simple, graphical test. BMJ. 1997;315:629-34 https://doi.org/10.1136/ bmj.315.7109.629.

22. Lin L, Chu H. Quantifying publication bias in meta-analysis. Biometrics. 2018 74(3):785-94 https://doi.org/10.1111/biom.12817.
23. Vevea J, Carol M. Woods. "Publication bias in research synthesis: sensitivity analysis using a priori weight functions". Psychol Methods. 2005;10(4):428-43.

24. Beal DJ, Corey DM, Dunlap WP. On the bias of Huffcutt and Arthur's (1995) procedure for identifying outliers in the meta-analysis of correlations. J Appl Psychol. 2002;87(3):583-9 https://doi.org/10.1037/0021-9010.87.3.583.

25. Greenhouse JB, lyengar S. Sensitivity analysis and diagnostics. In: Cooper H, Hedges LV, Valentine JC, editors. The handbook of research synthesis and meta-analysis; 2009. p. 417-33. Russell Sage Foundation.

26. Borenstein M, Hedges L, Higgins J, Rothstein H. Comprehensive Metaanalysis (Vers. 2). Englewood Cliffs: Biostat. Inc; 2005.

27. Shi $L$, Lin $L$. The trim-and-fill method for publication bias: practical guidelines and recommendations based on a large database of metaanalyses. Medicine (Baltimore). 2019;98(23):e15987 https://doi.org/10.1097/ MD.0000000000015987.

28. Getiye, Fantahun. Factors associated with perinatal mortality among public health deliveries in Addis Ababa, Ethiopia, an unmatched case control study. BMC Pregnancy Childbirth. 2017;17:245 https://doi.org/10.1186/ s12884-017-1420-7.

29. Aragaw YA. Perinatal Mortality and associated Factor in Jimma University Specialized Hospital, South West Ethiopia. GynecolObstet (Sunnyvale). 2016; 6:409 https://doi.org/10.4172/2161-0932.1000409.

30. Yirgu R, Molla M, Sibley L, Gebremariam A. Perinatal Mortality Magnitude, Determinants and Causes in West Gojam: Population-Based Nested CaseControl Study. PLoS ONE. 2016;11(7) https://doi.org/10.1371/journal.pone. 0159390.

31. Goba GK, Tsegay H, Gebregergs GB, Mitiku M, Kim KA, Alemayehu M. A facility-based study of factors associated with perinatal mortality in Tigray, northern Ethiopia. Int J Gynaecol Obstet. 2018;141(1):113-119. https://doi. org/10.1002/ijgo.12438. Epub 2018 Jan 31. PMID: 29318613.

32. Andargie $G$, Berhane $Y$, Worku A, Kebede $Y$. Predictors of perinatal mortality in rural population of Northwest Ethiopia: a prospective longitudinal study. BMC Public Health. 2013;13:168 https://doi.org/10.1186/1471-2458-13-168.

33. Nkwo, et al. Correlates of poor perinatal outcomes in non-hospital births in the context of weak health system: the Nigerian experience. BMC Pregnancy Childbirth. 2014;14:341 http://www.biomedcentral.com/1471-2393/14/341.

34. Fawole AO, Shah A, Tongo O, Dara K, El-Ladan AM, Umezulike AC, Alu FE, Eniayewun $A B$, Fabanwo $A O$, Adewunmi $A A$, et al. Determinants of perinatal mortality in Nigeria. Int J Gynaecol Obstet. 2011;114(1):37-42 Published online 2011 Apr 12. https://doi.org/10.1016/j.ijgo.2011.01.013.

35. Owolabi T, Fatusi AO, Kuti O, Adeyemi A, Faturoti SO, Obiajuwa PO. Maternal complications and perinatal outcomes in booked and unbooked Nigerian mothers. Singap Med J. 2008;49(7):526-31.

36. Ekure EN, Ezeaka VC, Iroha E, E-O MTC. Prospective audit of perinatal mortality. Niger J Clin Pract. 2011;14(1):88-94 https://doi.org/10.4103/11193077.79271. http://www.njcponline.com.

37. Schmiegelow C, Minja D, Oesterholt M, Pehrson C, Suhrs HE, Boström S, Lemnge M, Magistrado P, Rasch V, Lusingu J, et al. Factors associated with and causes of perinatal mortality in northeastern Tanzania. Acta Obstet Gynecol Scand. 2012;91(9):1061-8 https://doi.org/10.1111/j.1600-0412.2012.01478.x.

38. Habib NA, Dalveit AK, Mlay J, Oneko O, Shao J, Bergsjø P, Lie-Nielsen E, Lie RT. Birthweight and perinatal mortality among singletons and twins in North-Eastern Tanzania. Scand J Public Health. 2008;36(7):761-8 https://doi. org/10.1177/1403494808089559. Epub 2008 Aug 6.

39. Feresu, et al. Incidence of stillbirth and perinatal mortality and their associated factors among women delivering at Harare Maternity Hospital, Zimbabwe: a cross-sectional retrospective analysis. BMC Pregnancy Childbirth. 2005;5:9 https://doi.org/10.1186/1471-2393-5-9. http://www. biomedcentral.com/1471-2393/5/9.

40. Moyer, et al. Predictors of stillbirths and neonatal deaths in rural western Uganda. Int J Gynecol Obstet. 2016;134:190-3.

41. Engmann C, et al. Stillbirths and early neonatal mortality in rural northern Ghana. Tropical Med Int Health. 2012;17(3):272-82 https://doi.org/10.1111/j. 1365-3156.2011.02931.x.

42. Koné, et al. Pregnancy-related morbidity and risk factors for fatal foetal outcomes in the Taabo health and demographic surveillance system, Côte d'voire. BMC Pregnancy Childbirth. 2018;18:216 https://doi.org/10.1186/ s12884-018-1858-2.

43. Diallo AH, Meda N, Zabsonré E, et al. Perinatal mortality in rural Burkina Faso: a prospective community-based cohort study. BMC Pregnancy Childbirth. 2010:10:45 http://www.biomedcentral.com/1471-2393/10/45. 
44. Yego, et al. A case-control study of risk factors for fetal and early neonatal deaths in a tertiary hospital in Kenya. BMC Pregnancy Childbirth. 2014;14: 389 https://doi.org/10.1186/s12884-014-0389.

45. Musafili A, Essén B, Baribwira C, Selling KE, Persson LÅ. Social equity in perinatal survival: a case-control study at hospitals in Kigali, Rwanda. Acta Paediatr. 2015;104(12):1233-40. https://doi.org/10.1111/apa.12951.

46. Kulmala T, Vaahtera M, Rannikko J, Ndekha M. Timothy Cullinan4, MarjaLeena Salin and per Ashorn. The relationship between antenatal risk characteristics, place of delivery and adverse delivery outcome in rural Malawi. Acta Obstet Gynecol Scand. 2000;79:984-90 ISSN 0001-6349.

47. Osman NB, Challis K, Cotiro M, Nordahl G, Berström S. Perinatal outcome in an obstetric cohort of Mozambican women. J Trop Pediatr. 2001;47(1):30-8 https://doi.org/10.1093/tropej/47.1.30.

48. Sterne JA, Egger M. Funnel plots for detecting bias in meta-analysis. J Clin Epidemiol. 2001;54(10):1046-55 https://doi.org/10.1016/s0895.

49. Higgins JP, Thompson SG. Quantifying heterogeneity in a meta-analysis. Stat Med. 2002;21(11):1539-58 https://doi.org/10.1002/sim.1186.

50. Rothstein HR, Sutton AJ, Borenstein M. Publication Bias in Meta-Analysis. 2005. https://doi.org/10.1002/0470870168.

51. Murad $\mathrm{MH}, \mathrm{Chu} H$, Lin $\mathrm{L}$, et al. The effect of publication bias magnitude and direction on the certainty in the evidence. BMJ Evid-Based Med. 2018;23:84-6.

52. Esterhuizen TM, Thabane L. Con: meta-analysis: some key limitations and potential solutions. Nephrol Dial Transplant. 2016;31(6):882-5 https://doi. org/10.1093/ndt/gfw092. PMID: 27217394.

\section{Publisher's Note}

Springer Nature remains neutral with regard to jurisdictional claims in published maps and institutional affiliations.

Ready to submit your research? Choose BMC and benefit from:

- fast, convenient online submission

- thorough peer review by experienced researchers in your field

- rapid publication on acceptance

- support for research data, including large and complex data types

- gold Open Access which fosters wider collaboration and increased citations

- maximum visibility for your research: over $100 \mathrm{M}$ website views per year

At $\mathrm{BMC}$, research is always in progress.

Learn more biomedcentral.com/submissions 